Derechos reservados de El Colegio de Sonora, ISSN 1870-3925

\title{
Epidemiología sociocultural: propuestas y posibilidades
}

\section{Eduardo L. Menéndez*}

Resumen: Este artículo describe y analiza procesos de divergencia, convergencia y complementación entre la epidemiología y la antropología médica, con el objetivo de fundamentar el desarrollo de la epidemiología sociocultural en México. Se examinan en particular aspectos donde se observan dificultades de articulación entre ambas disciplinas y que se refieren a la posibilidad de establecer generalizaciones, a las concepciones sobre prevención, a la confiabilidad de los datos cualitativos y de los estadísticos, a los criterios de selección de informantes, que son discutidos a través de propuestas epidemiológicas y socioantropológicas respecto de la pobreza, el género, el racismo o el consumo de alcohol concernientes a procesos de salud/enfermedad/atención (s/e/a). En todos ellos se analizan los aspectos divergentes, pero también los que favorecen la complementación, lo cual no niega la existencia de una fuerte tendencia a la polarización entre ambas disciplinas, que, sin embargo, consideramos que podemos reducir y superar a través de procedimientos que favorecen el desarrollo de una epidemiología sociocultural pensada no como disciplina diferenciada, sino como una articulación entre los enfoques epidemiológicos y los socioantropológicos. Nos parece que uno de los principales mecanismos que posibilita dicha articulación lo constituye la problematización del proceso de s/e/a estudiar, que incluye, a su vez, la problematización de los presupuestos teóricos, empíricos y técnicos de los propios investigadores.

Palabras clave: epidemiología sociocultural, metodología, venganza de sangre.

\footnotetext{
* Investigador del Centro de Investigaciones y Estudios Superiores en Antropología Social (CIESAS), Juárez 87, Colonia Tlalpan, C.P. 14000 México, D. F. Correo electrónico: emenendez1@yahoo.com.mx
} 
Abstract: This article contains a description and analysis of divergence, convergence and complementation processes between epidemiology and medical anthropology, with the purpose of contributing to the development of sociocultural epidemiology in Mexico. Particular issues are analyzed concerning problems with linking both disciplines, and which allude to the possibility of establishing generalizations, notions of prevention, validity and reliability of qualitative and statistical data, and criteria for informant selection, points which are discussed in terms of epidemiological and socio-anthropological approaches to poverty, gender, racism or alcohol consumption in the health/disease/care process. Divergent and convergent issues are analyzed for all these topics, which does not negate a strong trend toward polarization between both disciplines. Even so, we consider that this can be reduced and surmounted through strategies aimed at developing a sociocultural epidemiology conceived not as a discipline but as a link between epidemiological and anthropological approaches. One of the main strategies is a reflection on the health process under study, which includes an in-depth discussion of the researchers' own theoretical, empirical and technical assumptions.

Key words: sociocultural epidemiology, methodology, blood revenge.

En este trabajo analizaré procesos de divergencia, convergencia y complementación que operan entre la epidemiología y la antropología médica, con la intención de contribuir al desarrollo de la epidemiología sociocultural en México, tendencia teórico-metodológica que con este nombre, o con los de etnoepidemiología o etnopsiquiatría, se ha desarrollado desde hace más de treinta años, especialmente en Canadá, los Estados Unidos y en algunos países latinoamericanos (Almeida Filho 2000; Gaines 1992; Massé 1995; Menéndez 1990a). Mi análisis refiere a materiales producidos en los Estados Unidos y en países europeos, pero básicamente a la producción epidemiológica y antropológica latinoamericana, y en particular a la realizada en México. Y es a partir de ellos que considero que la epidemiología sociocultural se caracteriza por varios rasgos, pero en particular por tres. En primer lugar, por plantear la necesidad de incluir en los estudios de los procesos de salud/enfermedad/atención (de ahora en adelante procesos de s/e/a) no sólo los aspectos sociales, sino también los culturales y los económico-polí- 
ticos, junto, por supuesto, con los biológicos y ecológicos. Subrayo que estos aspectos deben ser tratados no sólo como variables epidemiológicas, sino sobre todo como procesos socioculturales y bioecológicos.

En segundo lugar, por proponer un tipo de trabajo que realmente utilice y articule las aproximaciones estadística y cualitativa.Y tercero, por la aplicación de un enfoque relacional que incluya no sólo los diferentes factores que operan respecto de un problema determinado, sino que incorpore el conjunto de actores sociales significativos que viven, sufren y actúan respecto de dicho problema.

Existen otras características, pero dados los objetivos de este artículo, sólo subrayo estas tres, aunque reconozco que estas propuestas pueden ser consideradas innecesarias por epidemiólogos y antropólogos que podrían señalar que lo propuesto ya se hace en México. Esto en parte es correcto, ya que algo se hace, aunque no demasiado, y frecuentemente en forma sesgada, dado que, por ejemplo, si bien los estudios epidemiológicos y socioantropológicos realizados en México sobre la distribución de los padecimientos o el significado de los mismos toman en cuenta los procesos sociales, observamos, sin embargo, que la mayoría de la producción mexicana utiliza muy escasamente los procesos económico-políticos, pese a la pertinencia que tienen para la compresión y/o intervención respecto de problemas de salud prioritarios.

Reiteradamente, procesos culturales de alta complejidad son excluidos o convertidos por los epidemiólogos en variables esquemáticas y empobrecidas. A su vez, la mayoría de los antropólogos no describen ni analizan las características y procesos biológicos de los padecimientos. Más aún, "los antropólogos sociales y culturales siguen empeñados en perpetuar dicotomías como innato/aprendido, animalidad/humanidad, genético/ambiental, etcétera, que reflejan un profundo desconocimiento de la biología de los últimos veinticinco años" (Llobera 1990,129).

Estas dos disciplinas no incluyen en sus estudios un fenómeno de la importancia del racismo, que, como sabemos, caracteriza gran parte de las relaciones sociales desarrolladas entre nosotros, y especialmente algunas organizadas en torno a los procesos de s/e/a, como son las relaciones entre personal de salud y pacientes.

En la mayoría de los países americanos se han aplicado políticas eugenésicas que afectaron sobre todo a ciertos sectores sociales. Durante las décadas de 1960 y 1970 miles de mujeres fueron esterilizadas sin consentimiento en los Estados Unidos; dichas mujeres eran de origen afroamericano, mexicano, puertorriqueño y aborígenes americanos (Stern 2006). En la década de los noventa se calcula que 250 mil mujeres de origen indígena fueron esterilizadas en Perú (Miranda y Yamin 2004). Y en México se han 
reiterado denuncias de esterilizaciones no sólo a mujeres, sino también a varones de diferentes grupos étnicos.

Pese a ello, no contamos con una epidemiología de la esterilización en términos de su distribución según género, edad, pertenencia étnica, nivel socioeconómico, religión, etcétera, que incluya el sentido y significado de estas esterilizaciones para quienes las decidieron y para quienes las sufrieron. Como sabemos, en los Estados Unidos las esterilizaciones se aplicaron como parte del programa contra la pobreza, y en América Latina dentro de los programas de planificación familiar y de salud reproductiva.Y aunque es obvio, debemos recordar que dichas esterilizaciones fueron aplicadas por personal de salud.

Una revisión, inclusive superficial, de los estudios epidemiológicos y antropológicos respecto de muy diferentes procesos de s/e/a evidencia que la mayoría de los mismos centran sus preocupaciones en un solo actor social, es decir, se caracterizan por ser a-relacionales, como lo hemos analizado en varios trabajos (Menéndez 1997, 1998a, 2002, 2006).

\section{La venganza de sangre como problema epidemiológico}

Mi preocupación se basa además en que la carencia de la aplicación sistemática de una epidemiología sociocultural — junto con otros procesos — está dejando sin descripciones, explicaciones y propuestas de intervención algunos de los principales problemas sociales y de salud colectiva que aquejan a la población mexicana.

Para precisar lo que estamos proponiendo, comentaré una experiencia desarrollada en la vieja Escuela Nacional de Salud Pública, en la cual una parte importante del aprendizaje de las técnicas epidemiológicas se realizaba a través de un trabajo de campo que duraba alrededor de un mes y generalmente se llevaba a cabo en localidades de entre 10 mil y 20 mil habitantes.

En 1978, es decir, hace treinta años, realizamos un trabajo de campo de este tipo en una comunidad de Michoacán situada casi al borde de la denominada "tierra caliente". Era una comunidad de 12 mil habitantes y en la cual hicimos un estudio epidemiológico para saber de qué había enfermado la población en las últimas dos semanas, así como una investigación sobre uso de servicios de salud.

Yo realicé algunas de las encuestas a la población, y en una de las entrevistas ocurrió un hecho significativo. Llamé a la puerta de la casa, y salió a atenderme una joven de unos dieciséis años, quien me dijo que sus padres no estaban, y entonces decidí hacerle la encuesta a ella. Terminada la entrevista, me despedí pidiéndole que saludara a sus padres de parte mía. Y 
entonces la joven me contó que sus padres estaban muertos, que habían sido asesinados hacía poco tiempo; que no sólo los habían matado a los dos, sino que a su padre le habían sacado los ojos. Más aún, me confió que ella estaba aprendiendo a manejar un fusil para vengarse, dado que sólo tenía un hermano de ocho años, y estaba muy chiquito. Sus hermanos mayores residían desde hacía varios años en los Estados Unidos.

Me dijo además que dieron muerte a sus padres porque unas vaquitas habían invadido el predio del vecino que los mató, y que además el asesino se había fugado y estaba libre. Pero también me explicó que entre ambas familias había una larga historia de mutuos asesinatos.

La joven dio mucha más información, que no es necesario presentar ahora, porque en parte la he relatado en otros trabajos, aunque nunca en forma integral. Hacía cerca de dos años que yo vivía en México y nunca había escuchado hablar de este tipo de asesinatos, que en terminología antropológica tiene un nombre técnico, se llama "venganza de sangre", y ha sido estudiado en muy diferentes contextos, especialmente en grupos africanos.

Como además de trabajar con esta comunidad, teníamos también que estudiar una más pequeña de unos mil habitantes, situada a unos siete kilómetros de distancia de la anterior, aproveché la ocasión para preguntar a los entrevistados si tenían referencias de este tipo de hechos. Este segundo estudio se basaba en entrevistas en profundidad. Dos personas nos comentaron no sólo que estos hechos ocurrían, sino que estaban muy extendidos en la zona. Y me narraron varias características de los mismos.

Quiero señalar que a partir de nuestro estudio epidemiológico pudimos constatar que el homicidio constituía en estas comunidades una de las principales causas de muerte en varones en edad productiva; es decir, estamos hablando de un problema epidemiológico importante por lo menos a nivel local y regional, y del cual forma parte la venganza de sangre. Por supuesto que ni en los certificados de defunción ni en los diagnósticos médicos surgía la existencia de este tipo de homicidios, que justamente sólo se registraban como homicidios.

A partir de estos datos, pregunté a personas del equipo de trabajo si conocían este tipo de hechos, y varios respondieron que sí. Más tarde pregunté a algunos salubristas de la Escuela de Salud Pública, y también algunos reconocieron la existencia de estos hechos, pero no sabían de ningún estudio epidemiológico sobre los mismos. Tampoco pude detectar estudios antropológicos específicos. Quiero consignar que hasta la actualidad no conozco estudios antropológicos ni epidemiológicos que traten este tipo de homicidios en México. ${ }^{1}$

\footnotetext{
${ }^{1}$ Si bien no conozco estudios sobre venganza de sangre publicados en México, debo señalar que investigadores de la relevancia de A. Ysunza y de P. Hersch me han comunicado recientemente que en tra-
} 
En sucesivos trabajos de campo realizados en los cuatro años siguientes traté de reunir información sobre la existencia y características de estos hechos. Y verifiqué no sólo la existencia de venganza de sangre en varios contextos nacionales, sino que obtuve datos sobre algunas de sus características, de las cuales sólo señalaré tres. La primera indica que la venganza de sangre, si bien se lleva a cabo a través de la acción de uno o de varios individuos, implica una relación según la cual la venganza no sólo se puede ejercer sobre el individuo que mató previamente y del cual hay que vengarse, sino que también se puede ejercer sobre todo familiar cercano, especialmente si el sujeto no está cuando se lo va a asesinar. Más aún, la venganza legitima el homicidio de todos los miembros del grupo familiar que encuentren los agresores en el momento de ejercer su venganza, incluidos niños y mujeres embarazadas. En gran medida constituye un asesinato corporativo tanto en términos de homicidas como de asesinados, pero sobre todo la venganza de sangre es parte de un sistema de relaciones sociales, familiares y comunitarias.

La segunda característica es que el asesinato debe incluir acciones sobre el cuerpo del sujeto asesinado; el cuerpo debe ser marcado y hasta despedazado. Y tercero, la venganza de sangre representa un acto público que, en la mayoría de los contextos donde conseguimos información, no se oculta.

Obtuve dicha información entre los años 1978 y 1982, y como podemos observar, algunos de sus rasgos son los que caracterizan en la actualidad a ciertas formas de matar del crimen organizado, y especialmente a los asesinatos del denominado narcotráfico. Durante los últimos años, y en diversas zonas del país, han aparecido cadáveres decapitados, con las manos mutiladas y/o con los testículos quemados, los cuales constituyen mensajes dirigidos a determinados sujetos y grupos, así como también posibilitan la presencia de este tipo de datos en los medios de comunicación masiva. Se mata, por lo tanto, a partir de pautas culturales y sociales —incluida la planificación del horror-, reconocidas por lo menos por una parte de las comunidades donde operan estos asesinatos.

Para evitar equívocos, aclaro que, por supuesto, la venganza de sangre no pretende explicar el denominado narcotráfico, cuyas raíces, como sabemos, están en leyes basadas en criterios biomédicos y legales que justifican la prohibición del consumo de sustancias consideradas adictivas, y que casi inevitablemente conducen a la emergencia del crimen organizado en torno a la producción y comercialización de dichas sustancias (Menéndez y Di Pardo 2006).

bajos realizados en zonas rurales del estado de Puebla, así como en la costa de Oaxaca, verificaron la existencia de este tipo de venganzas. 
Me interesa señalar que la apropiación por parte del crimen organizado de procesos sociales y culturales resignifican y legitiman sus acciones, o por lo menos establecen un reconocimiento social de las mismas, más allá del repudio individual y colectivo respecto de dichos hechos. Estas actividades delictivas dan lugar a muy altas tasas de homicidios en países como Brasil, Colombia y México, que no son observadas en otros contextos sociales donde también existe un notorio desarrollo de actividades delictivas organizadas en torno a las drogas consideradas adictivas. Por lo tanto, estas altas tasas de asesinatos ocurren en sociedades donde, por lo menos en parte, aparecen legitimados culturalmente aun cuando puedan ser cuestionados socialmente.

Ahora bien, ¿quién estudia estos procesos, y no sólo en términos de variables, desde una perspectiva epidemiológica que incluya por lo menos una parte de los aspectos que acabo de mencionar? Que yo sepa, no lo estudian los epidemiólogos, ni los profesionales de la medicina social, ni los antropólogos médicos, ni los que estudian actualmente la violencia en México. Yo mismo tardé muchos años en dar cuenta de estos datos y, como lo apunté, nunca los describí integralmente.

Subrayo que el caso presentado constituye sólo un ejemplo de toda una serie de problemas que ameritan el desarrollo de una epidemiología sociocultural que entre nosotros se da en forma reducida y acotada. Y así, por ejemplo, carecemos de una corriente de estudios sobre los infanticidios, sobre el notable incremento de la impotencia sexual masculina, sobre la esterilización sin consentimiento informado en mujeres en edad reproductiva, sobre el papel del racismo en el desarrollo de los padecimientos. Carecemos de estudios que expliquen realmente por qué, pese a las dos y media “décadas perdidas" de 1980, 1990 y parte del 2000, mejoran, en lugar de empeorar, algunos de los principales indicadores de salud tanto en México como en toda América Latina (Menéndez 2005a, Organización Mundial de la Salud [OMS]/Organización Panamericana de la Salud [OPS] 2002; Secretaría de Salud 2001a, 2001b).

Es por estas omisiones y simplificaciones que necesitamos impulsar el desarrollo de estudios epidemiológicos socioculturales, debido además a que los procesos señalados no son secundarios en términos de salud colectiva. Como sabemos, el homicidio constituye una de las primeras causas de muerte en varones en edad productiva en varios países americanos, incluido México.

Mientras que el racismo representa entre nosotros uno de los procesos sociales más negativos que, entre otras cuestiones, explica que sean nuestros grupos indígenas los que presentan siempre los indicadores más negativos de salud/enfermedad/atención, comparados con cualquier otro grupo social (Castellanos 2000; Instituto Nacional Indigenista [INI]/Programa de las Naciones Unidas para el Desarrollo [PNUD] 2000; Menéndez 2001a). 
Farmer ha propuesto recurrentemente incluir el racismo como parte central de una epidemiología del viH-sida y de la tuberculosis broncopulmonar, pero dicha propuesta no ha tenido repercusión en la epidemiología ni en los estudios sociológicos sobre el VIH-sida ni sobre tuberculosis broncopulmonar realizados en México. Farmer y Castro consideran el racismo como parte de la causalidad y de las condiciones de atención de este padecimiento, y en especial como parte sustantiva del sufrimiento de la población en general y en particular de las personas pobres y enfermas (Castro y Farmer 2003; Farmer 1992, 1997, 2003).

La información sobre VIH-sida en la prensa escrita mexicana se concentra en mujeres y en población homosexual, con escasas referencias a la situación de los pobres. Y subrayemos que el viH-sida constituye la enfermedad sobre la cual los periódicos mexicanos presentan mayor información, comparada con cualquier otro padecimiento (Menéndez y Di Pardo 2007. Es decir, la relación pobreza-enfermedad tiende a ser omitida por la prensa escrita.

La Organización Mundial de la Salud (OMS) reconoció a mediados de la década de los noventa que se estaban incrementando la pobreza y la extrema pobreza, sobre todo en los países no desarrollados, constituyendo la principal causa de mortalidad en dichos países. Si bien entre nosotros tenemos cada vez más investigaciones sobre la pobreza, son muy escasos los estudios sobre ésta y procesos de s/e/a que permitan ir más allá de las descripciones e interpretaciones tautológicas.

No contamos con estudios sobre toda una serie de procesos de s/e/a, pero además no se realizan investigaciones sobre problemas de los que reiteradamente se habla. Desde por lo menos la década de los setenta, se ha señalado que los estudios epidemiológicos no documentan ni analizan información sobre enfermedad en términos de sufrimiento humano, ni incorporan el sentido y significado que los sujetos y grupos —incluido el personal de salud — dan a los sufrimientos.

Carecemos en nuestros países de una epidemiología de la tortura, y no sólo de la tortura que ocurre en periodos más o menos excepcionales, sino de la que se aplica cotidianamente. Cuando organicé el primer número de la revista Nueva Antropología, dedicado a la antropología médica (1985), publiqué un trabajo de Yarzábal (1985) que describe en términos epidemiológicos la tortura como enfermedad endémica en Uruguay, que varios antropólogos y epidemiólogos cuestionaron por considerar que no era una problemática correspondiente a sus respectivas disciplinas.

La falta de estudios - y más aún de acciones - sobre estos y otros procesos de s/e/a expresan el peso de orientaciones técnico-científicas e ideológicas que caracterizan nuestra producción de conocimiento.

Y así por ejemplo, en el caso del racismo y sus implicaciones en los procesos de s/e/a, observamos una preocupación y desarrollo de estudios por 
parte de la epidemiología brasileña en los últimos años, que contrasta con la negación del problema, prácticamente, por parte de la epidemiología mexicana.

Basta comparar la producción epidemiológica a través de las investigaciones y de las reflexiones de sus salubristas y clínicos, así como de la producción de las principales revistas salubristas mexicanas y brasileñas, para observar estas tendencias diferenciales (Faerstein 2005; Fry et al. 2007; Monteiro y Sansone 2004). Recordamos que el análisis e interpretación de estas “ausencias" es también parte del trabajo de una epidemiología sociocultural.

El tipo de epidemiología sociocultural que propongo no sólo busca incluir procesos, problemas y perspectivas como los señalados, sino que su objetivo es también cuestionar los estereotipos que se constituyen tanto en el saber de los grupos sociales legos como de los profesionales respecto de los procesos de s/e/a, lo cual hemos desarrollado especialmente respecto del saber médico y paramédico sobre el alcoholismo (Menéndez y Di Pardo 1996, 2003), pero también en cuanto a otras problemáticas sobre las cuales trabajan organizaciones no gubernamentales e instituciones oficiales y privadas, como son las que tienen que ver con ciertos aspectos de la salud femenina, y en particular con la violencia masculina contra las mujeres.

Una parte de estos organismos y organizaciones han subrayado la importancia de los feminicidios, lo cual nos parece relevante y necesario, pero a menudo lo han estudiado de tal manera que distorsionan la realidad que describen y especialmente las características de la mortalidad por asesinatos en México. Según sus propuestas y estudios, las mujeres serían los principales sujetos de los homicidios, proponiendo como ejemplo el caso de "las muertas de Juárez”. Pero ocurre que el principal problema en términos epidemiológicos, inclusive en Ciudad Juárez, es el de los masculinicidios, ya que en América Latina, si bien los varones matan mujeres, sin embargo, la mayoría de los asesinos, pero también de los asesinados, son varones. El 90 por ciento de los asesinatos en la región, incluido México, es de varones contra varones, y sólo menos del 10 por ciento corresponde a asesinatos de mujeres por varones (Krug et al. 2003; Organización Panamericana de la Salud 2002; Secretaría de Salud 2001a, 2001b, 2004).

Esta tendencia se ha reiterado históricamente, por lo menos desde que contamos con información más o menos confiable. Más aún, estos datos son publicados a nivel nacional e internacional en revistas epidemiológicas y son parte de nuestras estadísticas vitales, y sin embargo se ha ido construyendo una representación social dominante que no sólo establece una imagen casi exclusivamente referida a los feminicidios realizados por varones, sino que oculta o por lo menos silencia que los asesinados son básicamente varones, 
constituyendo una de las primeras causas de mortalidad en varones en edad productiva, lo cual no ocurre en el caso de las mujeres, como lo evidencian los datos epidemiológicos oficiales y no oficiales.

Se estima que durante el lapso 2001-2006 en México hubo alrededor de 10 mil asesinatos generados por el narcotráfico. Durante los primeros seis meses del 2007 se registraron 1237 ejecuciones relacionadas con el narcotráfico, de las cuales 47 víctimas no han sido identificadas, 87 corresponden a mujeres y 1143 son varones asesinados. Es decir, sólo el 7 por ciento de este tipo de homicidios se ejerce contra la mujer, mientras que el 92 por ciento corresponde a varones (Oliver 2007).

La epidemiología de los homicidios producida por los estudios de género en México requiere de una radical revisión, dado que el núcleo de la cuestión no radica en los feminicidios ni en los hombres violentos reflexivos, sino en el asesinato de varones, en lo cual hacemos hincapié sin negar la existencia de varones violentos reflexivos y de asesinatos de mujeres.

Por supuesto que el trabajo epidemiológico no sólo busca develar y cuestionar las afirmaciones estereotipadas y además incorrectas como las señaladas, sino que también se propone establecer los significados que tiene la creación y difusión de estos estereotipos, dado que una epidemiología sociocultural es en gran medida una epidemiología de los significados de los diferentes sujetos y grupos involucrados con los procesos de s/e/a, incluidos los significados de los propios sujetos que estudian los procesos epidemiológicos. De allí que en términos de epidemiología sociocultural, lo que necesitamos explicar es por qué determinados organismos del Estado y organizaciones de la sociedad civil tratan de imponer este tipo de datos y de representaciones sociales, así como las funciones que cumplen y para quiénes las cumplen.

\section{Algunas afirmaciones y varias propuestas}

Con base en estos señalamientos, analizaré algunos aspectos y problemas referidos al desarrollo de la epidemiología sociocultural en México, constituyendo nuestra primera propuesta que dicho desarrollo debe basarse en la articulación y complementación entre la antropología médica y la epidemiología, a partir de ambas disciplinas y no sólo a partir de una de ellas en forma exclusiva o dominante.

Desde luego, hablar de epidemiología y de antropología médica supone una simplificación, ya que en el ámbito de ambas disciplinas existen varias tendencias, algunas de las cuales evidencian fuertes diferenciaciones entre sí 
(Menéndez 1998b). Pese a reconocer estas diferencias, sostengo que el desarrollo posible de una epidemiología sociocultural se basa en la complementación - y no en la oposición - de ambas disciplinas y de sus diferentes tendencias, lo cual no niega que dicha complementación puede gestarse más entre ciertas orientaciones que entre otras.

Aclaro que si bien propongo una epidemiología sociocultural producto de la articulación de diferentes perspectivas disciplinarias, no lo hago a partir de considerar que cada disciplina tiene realmente límites fijos, específicos y claramente diferenciados en términos epistemológicos, sino que lo hago problematizando la realidad por estudiar, y asumiendo que es a partir del problema que podemos desarrollar una articulación interdisciplinaria que supere los límites establecidos institucional y profesionalmente.

Dicha complementación debería estar basada en lo que cada disciplina - y corrientes disciplinarias - se propone obtener; lo que dice que hace y lo que realmente realiza, para así establecer con la mayor claridad posible lo que obtiene y lo que no puede obtener o presenta limitaciones para lograrlo. Para mí, la complementariedad debe pasar por establecer los aportes de cada disciplina, pero también por indicar con la mayor claridad posible los problemas que cada una evidencia al estudiar y/o intervenir sobre los procesos de s/e/a con los cuales trabaja.

Más aún, dicha complementación debiera pasar por cuestionar las relaciones de hegemonía/subalternidad que existen entre las mismas, así como reflexionar sobre los estereotipos que cada una tiene de la otra. Según Inhorn, antropóloga médica especializada en enfermedades infecciosas, si bien ambas disciplinas presentan diferencias importantes, las similitudes son mayores que las diferencias $(1995,287)$.Y señala, por ejemplo, que ambas son disciplinas observacionales y no experimentales; para las dos la principal fuente de información sigue siendo la palabra del encuestado o del entrevistado, y ambas tienen una posición marginal respecto de la biomedicina.

Pese a estas y otras semejanzas, cada una de estas disciplinas tiende a subrayar ciertas características que acentúan las diferencias, y que en muchos aspectos básicos constituyen estereotipos. Inhorn analiza cinco estereotipos que los antropólogos tienen respecto del trabajo de los epidemiólogos, concluyendo que los mismos tienden a distorsionar y malinterpretar dicho trabajo.

Por lo tanto, necesitamos problematizar nuestras disciplinas y la relación entre ambas. Un paso decisivo de la problematización sería establecer una lista de lo que puede ofrecer/obtener y de lo que no puede ofrecer/obtener cada una de estas dos disciplinas, y a partir de ello establecer la posibilidad/necesidad de complementación. Pero esta lista —o como se llamedebe surgir de lo que realmente se produce, y no de lo que se podría hacer 
pero casi no se aplica. Ésta es una de las tareas básicas que todos los comprometidos con el desarrollo de una epidemiología sociocultural deberíamos elaborar con base en nuestros respectivos campos de trabajo.

Considero que la complementación y articulación debe darse no forzando una integración que puede hacer perder las características básicas de cada disciplina, sino, por el contrario, respetando lo que cada una aporta a partir de sus propias características. En consecuencia, no propongo una nueva disciplina, dentro de la cual se disuelvan las dos disciplinas en cuestión, sino una articulación problematizada de las mismas.

Para observar con mayor claridad lo que quiero transmitir, presentaré algunas problemáticas que en cierta medida son complementarias y que se refieren a aspectos con los cuales se identifican respectivamente la epidemiología y la antropología médica. La primera cuestión alude a la posibilidad de establecer generalidades estadísticas por parte de la epidemiología y a la imposibilidad de establecerlas por parte de las aproximaciones antropológicas. No cabe duda que aquí hay un punto de diferenciación y divergencia muy fuerte, que, para mí, debe resolverse a partir de establecer con la mayor claridad posible lo que busca no sólo cada disciplina, sino cada investigador.

El núcleo del conflicto y del distanciamiento, según la mayoría de los analistas, radica en que la aproximación epidemiológica no sólo busca establecer generalidades de base estadística, sino que también cuestiona, desconfía, subalterniza la información producida por las técnicas cualitativas respecto de diferentes problemáticas, pero sobre todo en términos de que no podría establecer generalizaciones.

A su vez, los antropólogos médicos plantean que la información obtenida por observación o a través de pocos informantes entrevistados en profundidad es realmente la que posibilita producir información estratégica, considerando frecuentemente que la mayoría de la información generalizable obtenida por la epidemiología es superficial y no aporta demasiado a la compresión de los problemas, y menos aún en términos de intervención. La epidemiología estaría preocupada básicamente por la generalización, mientras que la antropología buscaría la profundización.

La mayoría de los antropólogos actuales reconocen sin demasiados problemas que utilizan una metodología que no posibilita establecer generalizaciones, y no sólo de tipo estadístico. Más aún, las corrientes dominantes entre la década de 1970 y la actualidad, y especialmente las fenomenológicas, consideran imposible establecer generalizaciones, afirmando que la búsqueda de las mismas distorsiona los procesos por estudiar, lo cual ahonda aún más las diferencias con la epidemiología.

Sin embargo, una parte de los antropólogos más o menos memoriosos recuerdan - y algunos usamos — la existencia de aproximaciones cualitati- 
vas que posibilitan cierto tipo de generalizaciones. Las dos principales metodologías que hacen posible las generalizaciones no estadísticas son las que utilizan el tipo ideal y las que usan modelos, las cuales no sólo posibilitan generalizaciones sino que sobre todo proponen interpretaciones o explicaciones respecto de los procesos analizados.

Las dos tienen elementos comunes, que no vamos a desarrollar, pero me interesa destacar que el tipo ideal — con este o con otros nombres - fue utilizado por Émile Durkheim y por Max Weber desde fines del siglo xIx y principios del xx, respectivamente. A su vez, la metodología que emplea modelos aparece identificada con las orientaciones teóricas estructuralistas, pero también con las historicistas, incluido el marxismo. Durante la década de los sesenta diversos analistas consideraron que los modos de producción descriptos y analizados por Marx eran sobre todo modelos, reconociéndolo como uno de los principales aportes metodológicos del marxismo.

Esta propuesta se desarrolló especialmente a partir del texto de Marx (1984) sobre las formaciones precapitalistas, cuyos materiales históricos y antropológicos sólo podían ser aceptados justamente en términos de modelos y no de realidades históricas. Pero el desarrollo más completo Marx lo realizó respecto del modo de producción capitalista, donde el modo de producción constituye una construcción metodológica y la historicidad hace referencia a las formaciones económico-sociales.

Debemos recordar además que el tipo ideal fue utilizado intensamente por la antropología de los Estados Unidos y de América Latina durante el lapso 1940-1970, especialmente a partir de sus propuestas sobre los tipos de campesinado y sobre el continuum folk-urbano que recurrían a las concepciones de Durkheim y de Weber, pero también de Marx en autores como E. Wolf o S. Mintz.

La mayoría de las propuestas de generalización que emplean actualmente los cualitativos constituyen variantes de estas dos formas de generalización. Al respecto, debemos recordar que Durkheim (1974) aplicó esta metodología al estudio del suicidio y Weber a los tipos de autoridad y dominación (Weber 1987), de tal manera que estos instrumentos de interpretación y generalización fueron desarrollados por diferentes tendencias teóricas y metodológicas, y aplicadas tempranamente al estudio de procesos de s/e/a.

Pero además las tipologías han sido instrumentos frecuentes tanto de la medicina clínica como de la epidemiología, dando lugar al desarrollo de propuestas tipológicas desde las ciencias médicas en relación con padecimientos específicos, como han sido las diferentes tipologías que se han propuesto respecto del consumo de alcohol normal y patológico, así como las tipologías referentes a estilos de vida y procesos de s/e/a. Como sabemos, en el caso del alcoholismo la tipología más compleja fue la propuesta por 
Jellinek, mientras que en el caso de los estilos de vida la más notable fue la desarrollada por Cassel.

Más allá de la viabilidad de estas tipologías y de las críticas que se han formulado a las mismas, me interesa subrayar que ambas vienen del campo de la biomedicina, e incluyen centralmente procesos socioculturales.

Pero además la construcción de tipologías constituye parte esencial del análisis estadístico, dado que, como señala Mora y Araujo —refiriéndose a los estudios de opinión pública-, la mayoría de la investigación cuantitativa se concentra en el uso de segmentaciones tipológicas y de tablas de contingencia de dos o tres variables, concluyendo que: "Las segmentaciones útiles son las que subdividen a una población en términos de unas pocas variables fuertes como para explicar muchos de los comportamientos relevantes" (2005, 470). Recordemos que tanto la segmentación como las variables fuertes se seleccionan a partir de hipótesis que se imponen a los datos; es decir, operan como tipos sociales.

En el caso de los modelos, personalmente he desarrollado la propuesta del modelo médico hegemónico ( $\mathrm{MMH})$, así como de otros modelos de atención/prevención de los padecimientos, aunque con menor elaboración metodológica que el primero. Los modelos son construcciones —al igual que los tipos ideales - que posibilitan la indagación de procesos específicos, y desde esta perspectiva, el manejo de modelos y de tipos ideales debe asumir desde el principio que el tipo y el modelo no equivalen a la realidad que quieren describir y explicar, sino que son construcciones basadas en la realidad. Y segundo, que su aplicación supone una relación constante entre modelo/tipo e historicidad, siendo a partir de este juego que podemos simultáneamente dar cuenta de procesos y problemas específicos, así como proponer generalizaciones que van más allá de lo específico (Menéndez 1990b; Menéndez y Di Pardo 1996).

Justamente Weber elaboró su concepción tipológica como una dialéctica constante entre tipo e historicidad, que es lo que he tratado de hacer modestamente respecto del saber médico en México, tanto en términos de un problema específico — saber médico y alcoholismo- como respecto de procesos más generales referidos a las características, funciones, situación y trayectoria del sector salud mexicano. Por lo tanto, y a partir del juego modelo/historicidad y de considerar realmente como provisional nuestra propuesta de modelos médicos, he descripto y analizado durante cerca de treinta años las características del sector salud y en particular el proceso de alcoholización, observando a través de estudios específicos la trayectoria y funcionamiento del sector salud y de la biomedicina respecto del alcoholismo, lo cual me permite revisar, confirmar y/o modificar periódicamente la formulación de modelos médicos. 
Si bien el modelo se construye a partir de datos empíricos, no lo reducimos a los datos empíricos observables, sino que trata de articular los procesos y los actores sociales a través de las relaciones inscriptas en lo observable, para proponer interpretaciones que van más allá de lo observable y de los procesos y fuerzas sociales manifiestas.

Hago hincapié en que estos modelos deben concebirse como construcciones provisionales, que no niegan, por ejemplo, las diferencias subjetivas y grupales de los médicos, que no imponen una homogeneización que anula las particularidades, ni pretenden encontrar las explicaciones del funcionamiento de las instituciones y del saber médico exclusivamente fuera de ellos, colocándolas en estructuras y fuerzas sociales que determinan los comportamientos médicos, como señala con acierto Campos $(2001,36)$.

Considero que la subjetividad y la diferencia emergen cuando aplicamos determinados criterios metodológicos y cuando referimos el modelo a la historicidad de los procesos, como hemos tratado de desarrollarlo a través de nuestras descripciones y análisis del saber, de las instituciones y del MMH respecto del alcoholismo (Menéndez 1990b, 1992; Menéndez y Di Pardo 1996, 2003, 2006.

Algo similar he estado haciendo con referencia al modelo de autoatención y al modelo que corresponde a los saberes populares, respecto de los cuales la revisión se basa sobre todo en el material surgido de las tesis de maestría y de doctorado que he dirigido en los últimos veinte años y que en su mayoría aluden a procesos de autoatención y a las características y usos de los saberes populares en muy diferentes contextos mexicanos. Pero subrayo que en todos los casos el núcleo metodológico hace referencia a la relación que establecemos entre modelo e historicidad.

Debemos recordar que por lo menos una parte de las propuestas de tipos ideales y de modelos se formula a partir de reconocer la gran complejidad que caracteriza a determinados procesos y problemas sociales por investigar, y que la cuestión no es simplificar dicha complejidad, sino producir los medios metodológicos que nos posibiliten aproximarnos a su descripción y comprensión. El primer paso es cuestionar la esperanza empirista de utilizar y describir todas las variables que operan respecto del proceso por analizar, dado que, como lo examinó brillantemente Gouldner (1977), de manera inevitable toda investigación, por empirista y positivista que sea, selecciona y trabaja con una determinada construcción de la realidad. El segundo es problematizar la realidad a partir del punto de vista del investigador y/o de los actores significativos, y el tercero, proponer hipótesis a través de las cuales se formulan los tipos o modelos, que a su vez precisan y generan nuevas hipótesis; éstas se exploran a través de los tipos y modelos. Y cuarto, evidenciar y cuestionar el modelo que llevamos adentro respecto de la realidad por 
estudiar, y que frecuentemente constituyen confirmaciones de nuestros presupuestos no explicitados.

En síntesis, el uso de tipos y modelos supone asumir que son construcciones metodológicas, que deben ser referidas a la historicidad de los procesos y que su formulación se hace a partir de problematizar la realidad por estudiar y de establecer determinadas hipótesis respecto de dicha realidad. Es con base en estas hipótesis que simultáneamente pueden proponerse interpretaciones y generalizaciones. En última instancia, los tipos ideales y los modelos generalizan hipótesis en términos de probabilidades y, por lo tanto, las hipótesis debieran hacer referencia a los aspectos nucleares del problema y/o proceso a estudiar y comprender.

Ahora bien, no conozco, por lo menos en relación con México, estudios en los cuales se analice desde perspectivas epidemiológicas y antropológicas la posibilidad de articular el tipo de generalización estadística y el que deviene del uso de tipos y modelos, así como cuáles son sus beneficios y limitaciones, y el tipo de complementación que demandaría.

Además, hay otros aspectos relacionados con la posibilidad de generalización que favorecen el distanciamiento entre ambas disciplinas, y de los cuales sólo seleccionaré uno. Como ya lo señalé, la epidemiología trata de establecer generalizaciones que vayan más allá de los contextos locales, mientras que gran parte de los antropólogos se asumen como estudiosos de lo local, pasando a ser secundario o directamente inexistente la necesidad de generalizar, pero también de comparar. Si bien el método comparativo caracterizó el desarrollo inicial de la antropología, fue perdiendo significación hasta casi desaparecer de los objetivos e intereses de las escuelas dominantes entre las décadas de los setenta y los noventa.

Lo que afirmamos no niega que a la epidemiología le pueden interesar problemas del ámbito local, comunitario o regional, pero frecuentemente necesita manejar la información en un espacio local que posibilite, a su vez, la generalización y la comparación. Además, los epidemiólogos pueden estudiar un foco infeccioso local o establecer un programa de vigilancia epidemiológica regional, pero su trabajo implica el uso de determinadas categorías y la producción de información que posibiliten su comparación con los datos obtenidos en otros contextos. Requieren, por lo tanto, no sólo generalizar más allá de lo local, sino también describir y analizar los datos locales a través de categorías universales.

Gran parte de la antropología médica, al colocar sus objetivos en el estudio de lo local y de lo emic, trabaja en torno al padecimiento (illness). Lo que importa son las características que adquiere una enfermedad no sólo en el ámbito local sino también en función de las categorías sociales formuladas y utilizadas por los sujetos y grupos que estudia. Por lo menos una parte de 
los antropólogos sostiene que a través de los síntomas de los sujetos locales se expresan los valores, creencias y significados de la cultura local.

Ésta ha sido la tradición fuerte de los estudios antropológicos sobre los procesos de s/e/a, por lo menos desde la década de los treinta, y que se expresa, por ejemplo, en los extraordinarios estudios de Mead (1957) sobre la fatiga en Bali, de Devereux (1937) sobre el homosexualismo entre los mohave o De Martino (1961) sobre el tarantulismo en comunidades del sur de Italia. Todos estos trabajos focalizan las características locales —en su mayoría culturales - que se expresan a través de los padecimientos, ya que lo que importa es dar cuenta de la estrecha relación que existe entre determinadas formas culturales y las características de los padecimientos tanto en términos de causalidad, de desarrollo, como de solución de los mismos, pero donde lo central lo constituye la interpretación cultural de los procesos estudiados.

La identificación de esta perspectiva con los trabajos de Kleinman por gran parte de los antropólogos regionales actuales expresa el desconocimiento de la trayectoria de los estudios de nuestra disciplina sobre los procesos de s/e/a, y del conjunto de trabajos que ha ido posibilitando el desarrollo de la epidemiología sociocultural (Menéndez 2002).

En función del peso dado a la dimensión simbólica relacionada especialmente con aspectos como el cuerpo o el sufrimiento, se han desarrollado ciertas concepciones y acciones que deben analizarse con sumo cuidado, no sólo en términos teórico-metodológicos sino también ideológicos. Me refiero a toda una serie de antropólogos que desde fines de la década de los ochenta y sobre todo durante la de los noventa nos hablan de biologías locales como expresión de la estrecha relación y significación que existe entre el cuerpo y las enfermedades en el seno de las culturas locales (Menéndez 2001a, 2002).

Considero que el desconocimiento de la trayectoria de la antropología, así como de los procesos económico-políticos e ideológicos dentro de los cuales operó, les permite proponer esta categoría sin tomar en cuenta que fueron antropólogos - y otros científicos - alemanes y centroeuropeos, entre las décadas de 1920 y de 1940 los que más trabajaron con la concepción de biologías locales, que terminaron siendo usadas como justificadoras de exterminios masivos.

Me interesa poner de relieve que estas propuestas fueron desarrolladas por algunos de los más importantes antropólogos alemanes, recordando que en ese momento la antropología alemana constituía una de las tres antropologías más importantes del mundo junto con la británica y la de los Estados Unidos, y se caracterizaba por su mayor desarrollo teórico y metodológico. Dichos antropólogos propusieron una relación entre lo biológico, 
lo étnico y lo popular (volk) en términos de una unidad particular que caracterizaba a ciertos grupos sociales y los diferenciaba radicalmente de otros grupos (Harding 1993; Jell-Bahlsen 1985; Menéndez 2001a; 2002). Dicha propuesta no estaba basada sólo en la raza, como se suele afirmar, sino en la unidad indisoluble etnos-raza-pueblo, que estos científicos e ideólogos proponían.

La elaboración de una epidemiologia sociocultural debe tener muy en cuenta las diferentes trayectorias que dan lugar a su desarrollo, pero incluyendo y reflexionando no sólo sobre los aspectos descriptivos, teóricos y metodológicos que podemos recuperar para legitimar dicha orientación epidemiológica, sino también para cuestionar las orientaciones que no sólo generaron explicaciones incorrectas, sino que posibilitaron el uso de la antropología y de la biomedicina con objetivos y consecuencias negativos, como fueron la exterminación de gitanos, judíos, eslavos y de otras minorías raciales.

No debemos olvidar que una parte de los estudios sobre higiene racial fueron desarrollados no sólo por la biomedicina sino también por la epidemiologia, y no únicamente en Alemania, sino además en la mayoría de los países europeos y en los Estados Unidos, y que en nombre de esa concepción eugenésica se hicieron notables aportes tanto clínicos como epidemiológicos. Las investigaciones de Eppinger sobre las funciones hepáticas desarrolladas durante la década de los treinta y primeros años de la década de los cuarenta posibilitaron extraordinarios avances en la comprensión e intervención clínica de dichas funciones, pero a partir de la muerte de cientos de sujetos - judíos en su mayoría - que fueron utilizados como cobayos humanos en el laboratorio especial que el nazismo construyó en Creta, para que Eppinger realizara sus notables investigaciones biomédicas. La primera encuesta de masas a escala mundial sobre tuberculosis broncopulmonar (TBC) llevada a cabo no sólo a través de interrogatorio médico, sino también de pruebas clínicas, fue aplicada al conjunto de la población alemana bajo el régimen nazi, constituyendo uno de los aportes fundamentales a la epidemiología de la tuberculosis broncopulmonar en el ámbito internacional (Harding 1993; Menéndez 1972, 2002; Proctor 1988).

Como lo he expuesto en varios trabajos, la negación y el olvido son parte de la continua deshistorización de las sociedades, y el desarrolllo de una epidemiología sociocultural supone una suerte de continua lucha contra el olvido, dado que en el pasado podemos encontrar aportes que todavía tienen notable vigencia y validez metodológica y teórica, como son, por ejemplo, las propuestas epidemiológicas de Cassel (Cassel 1964, 1976; Cassel y Tyroler 1988) o de Murphy (Dubreuil 1988; Murphy 1982), pero también 
para observar cómo fueron usados conceptos como el de biologías locales, que requieren de una reelaboración y uso cuidadoso de los mismos.

\section{Críticas mutuas}

Como ya lo indicamos, ambas disciplinas se han cuestionado mutuamente, y así los epidemiólogos sostienen que los antropólogos no establecen con claridad cuáles son sus criterios para seleccionar los informantes con los cuales trabajarán; que las formas de utilizar, por ejemplo, la técnica denominada bola de nieve conducen a que por lo menos una parte de los sociólogos y antropólogos recurran a los informantes que "pueden” y no a los que serían más idóneos para lo que quieren estudiar.

Y tienen razón, ya que gran parte de los estudios antropológicos y sociológicos de tipo cualitativo no establecen criterios claros de selección de sus sujetos de estudio, o lo que es más preocupante, establecen criterios de selección, y luego entrevistan a lo sujetos que pueden y no a los que debieran en términos de la metodología propuesta. Debo advertir que algo similar le ocurre a una parte de los epidemiólogos que se han dedicado en los últimos años a aplicar técnicas cualitativas, sin tener demasiada experiencia en ello.

La epidemiología sociocultural basa su trabajo en los denominados actores sociales significativos, los cuales deben ser considerados como significativos en función de la importancia que tienen respecto del proceso de salud por investigar, estableciendo por lo tanto criterios de selección que deben aplicarse para conseguir entrevistar y observar justamente a los sujetos que tienen que ver con la problemática que se quiere estudiar, y no sólo a cualquier sujeto que se deja entrevistar.

Personalmente estoy cada vez más preocupado por la calidad de la información que producimos los antropólogos a través de nuestras técnicas cualitativas, dado que toda una serie de procesos están conduciendo a un fuerte deterioro en la aplicación de las mismas. Presiones de muy diferente tipo que impulsan la productividad académica tienden a reducir no sólo el tiempo del trabajo de campo, sino además la posibilidad de asegurar una mínima calidad de la información obtenida. Se fomenta la rapidez en todos los pasos de la investigación, de tal manera que muchas instituciones financian básicamente proyectos que utilizan técnicas cualitativas que favorecen la urgencia, aun cuando se reduzca la profundidad y calidad de la información.

Desde esta perspectiva, el auge actual de determinadas técnicas de obtención de información no tiene tanto que ver con la calidad de ésta como con la rapidez con que se la obtiene, lo cual abarata costos y conduce a producir 
resultados más rápidamente. No es un hecho casual que toda una serie de instituciones financiadoras de organizaciones no gubernamentales (ONG) hayan impulsado especialmente el trabajo con los denominados grupos focales.

Las técnicas rápidas de obtención de información (RAP) tuvieron una notable difusión inicial, que luego quedó sobre todo confinada a su uso por una parte de las organizaciones no gubernamentales. Estas técnicas fueron tempranamente criticadas por epidemiólogos y antropólogos por considerar que el tipo de información obtenido no era confiable, porque eran utilizadas por personas sin formación antropológica para obtener material cultural complejo, y porque conseguían los datos de muy pocas personas, inclusive de una sola. Este material se tomaba a veces como prueba piloto, pero en otras ocasiones constituía la base a partir de la cual se generaban intervenciones sobre las comunidades (Herman y Bentley 1992; Menéndez 2001b, 2005b).

Considero que las técnicas rápidas (RAP) han tenido un fuerte impacto en el trabajo de campo de antropólogos que están realizando investigaciones académicas sobre procesos de s/e/a, de tal manera que no sólo entrevistan en profundidad a unos pocos informantes, sino que también para problemas tan graves como pueden ser las relaciones entre pobreza y VIH-sida o la vinculación de las violencias con los estilos de vida, aplican una sola entrevista, que frecuentemente es más una encuesta que una entrevista en profundidad. Más aún, si bien no generalizan estadística ni tipológicamente sus análisis a partir de los datos con muy escasos informantes, terminan hablando de los pobres, de los grupos étnicos o de los estratos sociales, que suponen en cada caso a millones de sujetos.

Subrayo que no cuestiono trabajar con escasos informantes y en profundidad para obtener información confiable y estratégica; todo lo contrario, pero para ello hay que trabajar realmente a fondo.

Especialmente entre las décadas de los cincuenta y de los setenta, una parte de los antropólogos que trabajaban con procesos de s/e/a estaban preocupados por la validez de la información obtenida de los informantes claves que entrevistaban; así les ocurría especialmente a investigadores interesados por problemas relacionados con el alcoholismo, como son los casos de $\mathrm{H}$. Murphy, R. Smart o G. Nateras. Pero estas preocupaciones casi han desaparecido, por lo menos entre nosotros; a veces tengo la impresión de que ya no interesa cómo se obtiene la información, ni la calidad de la misma, ni el papel del antropólogo en la producción de dicha información. Lo único que interesa es producir datos.

Toda una serie de orientaciones teóricas, inclusive algunas caracterizadas por su sofisticación, han favorecido esta manera de trabajar. Varias propuestas, surgidas especialmente de los denominados estudios culturales, han promovido 
que una parte de los antropólogos se conviertan en flâneurs o, si se prefiere, en turistas del conocimiento. Es como si aspiraran a ser una suerte de Walter Benjamin caminando y vuayerando por París, nada más que ahora pasearían por los hospitales o por las bibliotecas de la facultad de medicina, para contarnos sus narrativas (Peirano 1997).

Las propuestas relativistas que cuestionaron la relación verdad-no verdad en la investigación antropológica, especialmente desde la década de 1970, y que por supuesto no se reduce a Geertz y sus discípulos, favorecieron estos procesos, así como también las propuestas que basan la información en las narrativas, describiendo y analizando el discurso en términos del mismo, y sin tomar en cuenta el contexto ni las relaciones sociales y económico-políticas donde funcionan dichas narrativas (Bibeau y Corin 1995).

Para mí, las propuestas socioantropológicas debieran preocuparse no sólo por la capacidad estratégica de la información obtenida, sino también por la calidad y confiabilidad de dicha información. Es decir, tenemos la obligación metodológica de establecer y justificar cuáles son nuestros actores significativos, cuáles son los criterios de selección de los sujetos que representan a los mismos, cómo obtenemos la información y cómo aseguramos la confiablidad de ésta.

A su vez, el trabajo epidemiológico también ha recibido fuertes y reiteradas críticas, de las cuales sólo recordaré algunas. En primer lugar, los antropólogos sostienen que las técnicas estadísticas como la encuesta tienden a aislar a los sujetos que entrevistan en lugar de describirlos en términos de sus relaciones sociales, y que además no incluyen los contextos a partir de los cuales estos sujetos desarrollan sus vidas y sus significados. Más aún, las técnicas estadísticas eliminan los significados personales que los entrevistados tienen respecto de los datos que los encuestadores les solicitan.

Uno de los principios básicos de la metodología estadística, me refiero a la selección al azar de lo sujetos a ser encuestados utilizada por los epidemiólogos, desconoce en los hechos que los sujetos se caracterizan porque la mayoría de sus relaciones sociales básicas no son aleatorias, sino producto de la vida social dentro de la cual operan. De esta manera, la metodología de la encuesta ignora una de las propiedades básicas de la vida social, es decir, que los sujetos se relacionan y no por azar estadístico.

Diversos autores sostienen que las variables sociales y culturales que utiliza la epidemiología, como pueden ser estratificación social, pobreza o pertenencia étnica, se aplican sin establecer lo que significan estratificación social, pobreza y pertenencia étnica en términos teóricos, o por lo menos de procesos sociales empíricos. Estas y otras categorías como edad, rural/urbano, sexo o género son producto de procesos sociales; son parte de las repre- 
sentaciones sociales colectivas e inclusive de las luchas sociales que se han dado entre diferentes sectores sociales, como justamente es el caso de las categorías sexo/género. De esta manera, aparecen como categorías científicas y universales, cuando son resultado de procesos sociales, y por supuesto técnico-científicos, que organizan ciertos tipos de realidad, que la mayoría de los epidemiólogos no cuestionan ni analizan en sus consecuencias metodológicas. Más aún las estadísticas vitales, por ejemplo, se presentan al investigador como realidad objetiva, cuando las mismas constituyen construcciones metodológicas e ideológicas de la realidad (Lenoir 1993).

Los epidemiólogos suelen manejar estas variables y categorías como meros indicadores que posibilitan establecer determinadas correlaciones estadísticas en torno a dichas variables, pero sin incluir en sus análisis el significado que las mismas tienen respecto de los procesos estudiados (Massé 1995). O si lo hacen, generalmente sus propuestas son tautológicas, o simplifican la realidad a estudiar en términos tales que no sólo no la describen en profundidad, sino que no la utilizan eficazmente, como he tratado de evidenciarlo a través de mi análisis de la variable estilo de vida (Menéndez 1998b).

Esta tendencia la podemos observar sobre todo a través de una parte significativa de los estudios que sobre pobreza y salud se están desarrollando actualmente en América Latina, y que tienen la propensión a trabajar con la realidad en términos de variables y no de procesos sociales, simplificando y esquematizando los procesos que estudian, y además dejando de lado con frecuencia los procesos de violencia estructural que caracterizan a la pobreza latinoamericana actual.

Pero además tanto la epidemiología como la socioantropología, que estudian la pobreza y los procesos de s/e/a en México — según surge de una revisión bibliográfica y de algunas entrevistas que estamos realizando-, si bien han generado aportes, especialmente en términos estadísticos, lo que llama no obstante la atención es la pobreza de la información etnográfica, la reiteración de ciertas temáticas de escasa significación y la carencia de descripciones y análisis sobre aspectos decisivos de las relaciones entre pobreza y procesos de s/e/a.

Los especialistas regionales tienden a ignorar la producción de notables trabajos desarrollados desde la década de los sesenta por autores como Antonovski, Black, Farmer, Kosa, Massé, Riesman o Tousignant, quienes no sólo incluyen los procesos económico-políticos y los simbólicos en sus análisis sobre la relación entre pobreza y procesos de s/e/a, así como el racismo y la desigualdad socioeconómica como partes centrales de dicha relación, sino que además desarrollan conceptos como los de coping (Antonovski 
1979) o espacio de pobreza (Massé 1995; Tousignant 1989), que serían de suma importancia para explicar y para intervenir en la situación mexicana. ${ }^{2}$

La mayoría de los estudios manejan supuestos teóricos y empíricos que proponen que los estratos sociales más bajos se caracterizan por tener las más altas tasas de mortalidad y la menor esperanza de vida en comparación con cualquiera de los otros estratos sociales. Según estos estudios, los pobres se distinguen no sólo por ser más vulnerables a la mayoría de las enfermedades, sino por pagar más por su salud (Williams 1977).

Estas y otras características diferencian radicalmente a los más pobres del resto de los estratos sociales. Y es a similares conclusiones que llegan los estudios locales sobre pobreza y procesos de s/e/a, pero sin avanzar mucho más en sus interpretaciones.

Observamos que la mayoría de los estudios mexicanos sobre salud y pobreza, y especialmente los que se han realizado en torno a los programas contra la pobreza, dejan de lado no sólo las investigaciones, sino también las discusiones, reflexiones y aplicaciones que se hicieron sobre las políticas de atención primaria de salud y en particular respecto de las denominadas atención primaria comprensiva y atención primaria selectiva, desarrolladas entre fines de la década de los setenta y la de los noventa, lo cual constituye una grave omisión, ya que fue en gran medida a partir de los programas de atención primaria de la salud que ulteriormente se diseñaron y aplicaron las políticas focales o selectivas concernientes a la población en situación de pobreza y extrema pobreza.

El análisis y evaluación de las mismas posibilitaría explicar, por ejemplo, no sólo la trayectoria de los programas IMSS/COPLAMAR, Solidaridad, PROGRESA y Oportunidades, sino también la eficacia y las limitaciones de los mismos, recordando que dichos programas fueron organizados e impulsados por el Estado mexicano desde mediados de la década de los setenta hasta la actualidad para enfrentar determinados problemas $-\mathrm{y}$ especialmente los de enfermedad - que afectaban la situación de los sectores sociales más pauperizados de la sociedad mexicana, en particular en el medio rural.

Esos estudios y reflexiones tal vez ayudarían a nuestros especialistas en pobreza y salud a comprender lo que no pueden comprender — según lo

\footnotetext{
2 El concepto de coping ha sido utilizado y definido de muy diferentes maneras, siendo las dominantes las que han psicologizado este concepto, focalizando el papel del individuo. Antonovski, por el contrario, utiliza el concepto de coping (1979) a partir de sus análisis de la desnutrición, donde los procesos económico-políticos, y en particular las clases sociales, son centrales para explicar quiénes y por qué son desnutridos (1967), y la posibilidad de revertir o por lo menos paliar esta situación a través de los recursos de todo tipo utilizados para enfrentarla. En México el concepto de coping ha sido muy poco empleado, y casi exclusivamente por psicólogos, quienes lo han traducido como enfrentamiento, o por términos similares.
} 
explicitan varios de ellos mismos-, e inclusive a incluir en sus estudios y acciones lo que no incluyen (Grodos y Bethume 1988; La Forgia 1985; Menéndez 1993; Menéndez y Spinelli 2006; Paganini y Rice 1989; Rifkin y Walt 1998). Dado, además, que los estudios sobre pobreza y salud tienden a ignorar algunos de los principales aportes etnográficos que se han hecho en los últimos años respecto de población en situación de pobreza y perteneciente a diversos grupos étnicos, como son, por ejemplo, los estudios de Mendoza (1994, 2004) y de Ortega (1999). Si bien estos trabajos no tienen por objeto la pobreza, presentan no obstante información mucho más profunda, confiable y estratégica sobre procesos de s/e/a en población pobre, lo que posibilita comprender algunos de los problemas más lacerantes que padecen dichos grupos.

Más aún, los especialistas en pobreza tienden a ignorar los estudios desarrollados por médicos latinoamericanos y especialmente mexicanos (Celis y Navas 1970) entre las décadas de los cincuenta ysetenta, que evidencian una preocupación especial respecto de la pobreza como una de las principales causas de enfermedad y de las altas tasas de mortalidad, así como uno de los principales impedimentos para reducir los problemas de salud de la población mexicana. Toda una serie de estudios clínicos y epidemiológicos sobre la cirrosis hepática desarrollados durante las décadas de los cincuenta y sesenta conducirá a los especialistas mexicanos a colocar las causas de este padecimiento en la relación consumo de alcohol, desnutrición y pobreza, interpretación que a partir de la década de los setenta fue abandonada, en particular por los nuevos líderes académicos y profesionales (Menéndez 1990b, Menéndez y Di Pardo 2003).

El análisis de los materiales bibliográficos y de las intervenciones sobre pobreza y salud producidos desde la década de los sesenta posibilitaría a los especialistas actuales en este campo contar con explicaciones y estrategias de intervención que siguen siendo vigentes, así como desechar las que han evidenciado falta de eficacia. Este examen es pertinente porque las políticas y actividades que se están aplicando en la actualidad contra la pobreza,y especialmente las que tienen que ver con los procesos de s/e/a, reiteran, sin demasiados agregados, las que se vienen aplicando en México desde las fechas indicadas.

\section{Críticas epistemológicas, técnicas y de sentido común}

La revisión de las investigaciones epidemiológicas, especialmente las relacionadas con ciertos padecimientos, ha conducido a generar desde la década de 
1960 críticas recurrentes respecto de que lo básico - y a menudo lo único- que aportan la mayoría de los estudios epidemiológicos son mediciones, pero mediciones que no permiten comprender muchos de los procesos que miden, dado que tienden a desconocer la complejidad del campo social donde operan dichos procesos de s/e/a (Bibeau y Corin 1994). Esto, por supuesto, no niega los aportes epidemiológicos, sino que señala sus limitaciones.

Desde hace más de dos décadas estoy analizando los aportes epidemiológicos respecto del consumo de alcohol y de sus consecuencias en la salud de la población mexicana, y hago mías las conclusiones de dos de los más importantes especialistas contemporáneos sobre adicciones, incluidas las relacionadas con el consumo de alcohol: "Los estudios epidemiológicos sobre el consumo de drogas rara vez han abordado las verdaderas dificultades teóricas de esta problemática; predomina un tipo de investigación mecánica y reiterativa que trata al consumidor de drogas como un objeto de estudio totalmente divorciado de las condiciones culturales y de las instituciones sociales dentro de las cuales vive y consume drogas." (Edward y Ariff 1981, 291).

Más aún, reconocen que el alcoholismo no es fácil de estudiar, pues implica un conjunto de relaciones complejas y en constante cambio, y que justamente este es el tipo de problemas que debe enfrentarse metodológicamente en lugar de simplificar la realidad describiéndola a través de variables y de categorías aisladas, que no posibilitan entender lo que pasa con dicho padecimiento.Y recuerdo que estos especialistas en alcoholismo son clínicos y epidemiólogos.

Estas afirmaciones siguen siendo válidas para la mayor parte de la investigación epidemiológica que se realiza en México sobre consumo de alcohol y sus consecuencias (Menéndez 1990b; Menéndez y Di Pardo 2003, 2006). Pero es importante señalar que esta producción epidemiológica evidencia además serias incongruencias metodológicas, especialmente referidas a la calidad de la información que genera y analiza.

Desde por lo menos la década de los sesenta contamos con evaluaciones metodológicas que indican que las encuestas tienden a subregistrar el consumo de alcohol por parte de la población, y así R. Room, analizando los datos de la encuesta aplicada por Cahalan en 1964-1965 a escala nacional de los Estados Unidos, encuentra que los datos de esta encuesta sólo corresponden a 50 por ciento de la venta de vinos, a 55 por ciento de la venta de cerveza y a 55 por ciento de la venta de bebidas alcohólicas de alta graduación. Es decir, esta encuesta subregistra en más de 50 por ciento los volúmenes de bebidas alcohólicas consumidos por la población de los Estados Unidos, según los registros de venta. 
Recordamos que ambos son dos de los más importantes investigadores norteamericanos sobre alcoholismo. Por ello es fundamental señalar que a partir de entonces se verificaron estos hallazgos en otros contextos, y por lo tanto se recomendó no aplicar este tipo de instrumento para obtener datos confiables sobre consumo de alcohol. Más aún, una revisión de los estudios epidemiológicos basados en encuesta realizados en países como Canadá, Finlandia y los Estados Unidos concluyó que “proporcionan estimados del consumo per cápita equivalentes a entre 40 y 60 por ciento de los resultados obtenidos de la venta" (Pernamen 1975, citado en Organización Mundial de la Salud [OMs]/Organización Panamericana de la Salud [OPS] 2000, 36; véase también Midanik 1982).

Estos y otros analistas llegaron a la conclusión de que estas encuestas no detectan a los bebedores de mayor consumo - es decir, uno de los principales grupos de riesgo_- dado que dichos bebedores tienden a decir a sus encuestadores que no beben o beben muy poco alcohol, mintiendo intencionalmente. Más aún, esta omisión y deformación de la información se observa también en las entrevistas clínicas (Hammersley 1994; Menéndez y Di Pardo 1996, 2003; Seppa 2006).

Pese a que los especialistas nacionales tienen conocimiento de estas críticas, en México se han llevado a cabo desde fines de la década de 1980 cinco encuestas nacionales sobre consumo de alcohol y consumo de otras sustancias consideradas adictivas, pero sin incluir en las descripciones y análisis los sesgos que presenta la información obtenida, que no sólo subregistra el consumo general de alcohol, sino que subregistra el consumo de alguno de los principales grupos de riesgo. Más aún, se calcula que más del 50 por ciento del alcohol consumido en México es de producción y venta clandestinas, pero la mayoría de los epidemiólogos especializados en alcoholismo sólo estudian el alcohol a través de las encuestas citadas y/o de las cifras oficiales que no incluyen la producción y venta clandestina, lo cual acentúa todavía más el sesgo de sus descripciones y análisis, que no corresponden a los consumos reales de alcohol de la población mexicana.

Ahora bien, estos subregistros del consumo de alcohol no sólo los observamos en los estudios específicos realizados en México sobre dicho consumo, sino también en estudios sobre la violencia contra la mujer que tratan de correlacionar dicha violencia con el consumo de alcohol.Y así, por ejemplo, en la encuesta nacional sobre violencia contra la mujer realizada en México (Olaiz et al. 2003, 16) se presentan datos que indican que según las mujeres encuestadas 51 por ciento de ellas nunca toma bebidas alcohólicas, 43.6 por ciento dice beber ocasionalmente menos de una vez al mes y sólo 3 por ciento reconoce un consumo mayor al de una vez al mes. 
En ninguno de los casos señalados observamos una reflexión metodológica por parte de los investigadores que diseñaron y aplicaron estas encuestas - y que trabajan en dos de los principales institutos nacionales de salud - respecto de la confiabilidad de los datos estadísticos obtenidos, ni sobre su calidad, pese a que por lo menos una parte de dichos datos contradicen no sólo los datos de las estadísticas vitales, sino también el sentido común de cualquier persona que viva en México. La Secretaría de Salud (SSA) y el Instituto Nacional de Estadística, Geografía e Informática (INEGI) nos informan que desde la década de los ochenta la mortalidad por cirrosis hepática en mujeres que están entre los 35 y 64 años de edad es una de las primeras cinco causas de mortalidad.

Pero no sólo no observamos reflexiones metodológicas sobre la información obtenida, sino que ésta se utiliza como si realmente los datos correspondieran a la realidad de los consumos, no expresando los investigadores ninguna duda sobre la información que nos están presentando y a partir de la cual sacan conclusiones que pasan a ser parte de nuestras realidades epidemiológicas construidas por la epidemiología, pero que tienen poco que ver con la realidad de los consumos y de los usos de la población.

Desde hace años se han generado críticas consistentes respecto de las construcciones más o menos imaginarias que han concebido diferentes disciplinas, incluida la epidemiología — y por supuesto la antropología—, en relación con el alcoholismo (Room y Collins 1983), pero nuestros especialistas siguen sin asumir dichas críticas y estableciendo mediciones que no sólo no son válidas, sino que distorsionan la realidad.

Además las reiteradas encuestas epidemiológicas realizadas sobre consumo de alcohol sólo se dedican a obtener ciertos datos para medir consumo y para correlacionarlos con ciertas variables, pero sin producir información sobre aspectos económico-políticos, culturales, sociales, que son decisivos para poder diseñar y aplicar estrategias respecto de los problemas generados por el consumo de alcohol. Cada vez se habla más de la importancia de los estilos de vida, así como del cambio de los mismos, especialmente en mujeres y en adolescentes, para explicar las formas y volumen de consumo de alcohol por parte de los mismos, pero las encuestas señaladas casi no nos dicen nada sobre dicha variable en términos que nos puedan servir tanto para comprender como, sobre todo, para intervenir.

Existe además toda una serie de procesos epidemiológicos respecto de los cuales no contamos con información que nos permita comprenderlos, pese a lo sorprendente que son. Tenemos, por ejemplo, el caso del von o virus del Nilo, padecimiento detectado por primera vez en Uganda en 1937 y que fue encontrado en 1999 en seres humanos en los Estados Unidos. Para 2004 
se habían infectado 15 mil personas, 650 de las cuales murieron en dicho país, especialmente en las áreas del sureste, fronterizas con México.

Pese a que las condiciones geográficas y ecológicas son prácticamente idénticas en ambos lados de la frontera, y pese a que el principal vector de contagio es un mosquito que vive tanto en los Estados Unidos como en México, hasta 2006 no se había detectado el virus en humanos del lado mexicano.

Hay varias hipótesis concernientes a este proceso que van desde la negación epidemiológica del problema hasta la confusión de los casos del voN con dengue. Tal vez estaría ocurriendo lo que observé a fines de la década de los setenta y principios de la de los ochenta en varias zonas del país y especialmente en Yucatán, donde, pese a la existencia de condiciones ecológicas y ambientales y pese a la existencia del vector, los clínicos y epidemiólogos no detectaban el mal de Chagas, pues no lo reconocían a través de los indicadores diagnósticos que utilizaban (Menéndez 1981).

Pero lo cierto es que nuestros clínicos y epidemiólogos no detectan ni codifican enfermos ni muertos por el virus del Nilo, pese a su impacto creciente en la morbilidad y mortalidad de los norteamericanos y mexicanos que viven del otro lado de la frontera con mayor tránsito de personas a escala mundial. Justamente en El Paso se han descubierto a menudo casos de vON, por lo cual las autoridades sanitarias de Juárez, ciudad mexicana colindante con El Paso, “colocaron trampas para evitar que los mosquitos lleguen a esta ciudad” (La Jornada 2007).

Las críticas señaladas son frecuentemente correctas, y por eso la construcción de una epidemiología sociocultural implica reconocer las limitaciones de ambas disciplinas a partir de las cuales establecer una posible y necesaria complementación. Es decir, no permanecer en la crítica del Otro, sino asumir las críticas del Otro, para con base en ellas - y, por supuesto, de otros aspectos - favorecer una articulación metodológica y técnica.

Considero que estas limitaciones y diferencias no sólo existen, sino que es lógico que existan, pues surgen de las concepciones, hábitos profesionales, técnicas de investigación, objetivos diferenciales que cada disciplina ha procesado en su trayectoria profesional y académica. Es a partir de reconocer estas diferencias que hay que analizar lo que cada una puede y no puede realizar tanto en el ámbito metodológico general como respecto del análisis de problemas específicos.

Desde esta perspectiva, cada disciplina debiera reconocer sus aportes y sus limitaciones, así como cuestionar los aportes y señalar las limitaciones de la otra, pero para buscar una posible complementación y no para justificar las diferencias y distanciamientos. 


\section{La necesaria búsqueda de complementaciones}

Dicha complementación la consideramos necesaria por la creciente complejidad de los procesos de salud/enfermedad/atención que requieren de un trabajo articulado entre diferentes disciplinas, dadas las limitaciones y parcialidad de los enfoques, técnicas y marcos teóricos particulares.

La aproximación epidemiológica se maneja mejor con variables e indicadores de tipo biológico, ecológico y en menor medida sociales, teniendo dificultades para trabajar con indicadores y variables - y no digamos procesos- culturales. La mayoría de las orientaciones antropológicas trabajan muy poco con procesos biológicos, y se centran en los socioculturales. Tanto la epidemiología como la antropología médica actuales tienden a trabajar muy poco con indicadores o procesos socioeconómicos y menos aún económico-políticos. Y en el caso de México no trabajan con indicadores ni con procesos raciales ni racistas.

La articulación entre ambas perspectivas posibilitaría el desarrollo de una epidemiología no sólo del disease (enfermedad), sino también del illness (padecimiento), una epidemiología no sólo de los significados, sino además de las condiciones económico-políticas, una epidemiología no sólo de las representaciones, sino también de los comportamientos y de las experiencias.

Esta propuesta no surge de reflexiones teoricistas más o menos voluntaristas, sino de mi experiencia en el campo de la investigación, la docencia y la participación en grupos de análisis, desarrollada desde mediados de la década de los sesenta hasta la actualidad. En términos de investigación, nace de mi participación en estudios de comunidades rurales y urbanas que incluían central o tangencialmente las problemáticas de salud, así como de las investigaciones interdisciplinarias sobre enfermedades ocupacionales desarrolladas en Argentina. Deriva del estudio sincrónico y diacrónico realizado en Yucatán sobre Estado/sociedad civil y procesos de s/e/a, al igual que de toda una serie de pequeños estudios sobre procesos de autoatención y de medios de comunicación masiva. También surge de nuestros trabajos sobre el proceso de alcoholización y especialmente los centrados en los saberes médico y paramédico, así como del estudio interdisciplinario respecto de condiciones de mortalidad en la niñez en medios rurales y urbanos del estado de Guanajuato.

Durante dicho lapso desarrollé una intensa labor docente con antropólogos y con salubristas en varias instituciones nacionales y extranjeras, lo que condujo a producir cerca de cuarenta tesis de posgrado concluidas y cuyos autores trabajaron en su mayoría con perspectivas de lo que denominamos epidemiología sociocultural. 
Un importante componente ha sido mi participación en grupos de discusión y análisis de procesos de s/e/a, especialmente en grupos constituidos por psicoanalistas y psiquiatras con quienes desarrollé varias actividades y en particular el examen de materiales surgidos de sesiones clínicas. Como parte de este rubro incluyo además las sesiones de trabajo del seminario permanente de antropología médica (SPAM) desarrollado en el CIESAS durante cerca de veinte años y dedicado exclusivamente al análisis de investigaciones sobre procesos de s/e/a.

Es a partir de esta experiencia que he estudiado los aspectos que favorecen tanto las diferencias como las convergencias entre la antropología médica y la epidemiología. Concluyo que una real complementación sólo puede darse luego de reconocer las diferencias mutuas, así como asumir que cada una de estas disciplinas exige una formación profesional específica. Por estas y por otras razones, sostengo que es más factible y eficaz el desarrollo de una epidemiologia sociocultural a partir de la complementación interdisciplinaria que a través del desarrollo de una nueva disciplina.

Sin negar esta última posibilidad, considero que las convergencias y articulación pueden desarrollarse con mayor eficacia a través de un trabajo interdisciplinario que en la práctica de la interdisciplina reconozca y verifique esta posibilidad, sobre todo sus aportes. Es en función de ello que, a manera de ejemplo, trataré la problemática de la prevención, respecto de la cual observamos notorias diferencias en los usos de nuestras dos disciplinas.

Como sabemos, la epidemiología y el salubrismo en general se caracterizan por el escaso uso de la dimensión cultural respecto de la prevención; más aún, la biomedicina —incluida la epidemiología — suele considerar los saberes populares como factores que frecuentemente inciden en forma negativa sobre los procesos de salud/enfermedad/atención. Los perciben como saberes equivocados, juzgando explícita o implícitamente que la población no sólo carece de criterios de prevención, sino que rechaza ésta.

Sin negar totalmente estas afirmaciones, lo primero por recuperar es que todo grupo social, ajeno a su nivel de educación formal, genera y utiliza criterios preventivos respecto de por lo menos una parte de los padecimientos que los sujetos y grupos reconocen que están afectando real o imaginariamente su salud o aspectos de la vida cotidiana relacionados con la misma. No existen grupos, clases sociales o culturas que carezcan de estos saberes, dado que son básicos para su producción y reproducción biocultural.

La mayoría de los criterios y acciones preventivos generados por los grupos sociales son socioculturales, y el punto central para nosotros no radica tanto en considerarlos comportamientos erróneos o correctos, sino en asumir que los grupos producen y utilizan representaciones y prácticas sociales de prevención más allá de que éstas sean equivocadas o no. El desarrollo de 
criterios de prevención respecto de los hechos, factores y/o actores que amenazan real o imaginariamente a un grupo constituye un proceso estructural en el devenir de la vida de los grupos y sujetos sociales.

El reconocimiento y uso de estos procesos supondrían un cambio radical en la perspectiva salubrista, pues asumiría que los conjuntos sociales no carecen o son reacios a la prevención, dado que producen y usan saberes preventivos en su vida cotidiana. Reconocería que si bien los sujetos y grupos suelen rechazar determinadas concepciones y prácticas preventivas que propone el sector salud, ello no significa que se opongan o no utilicen saberes preventivos.

Además, en el caso mexicano la actitud receptiva de los sujetos y grupos sociales hacia las políticas de prevención se expresa a través de varios aspectos decisivos desde una perspectiva de salud pública, y de los cuales sólo citaré dos ejemplos. El primero nos recuerda que el sector salud mexicano ha logrado una de las más altas coberturas mundiales de vacunación que habría inmunizado a más de 97 por ciento de la población, lo cual implica reconocer que por lo menos la población no rechaza una de las principales estrategias de prevención biomédica.Y debemos subrayar que el esquema de vacunación aplicado en México implica inmunizar a los niños menores de seis años y a otros grupos etarios respecto de una gran variedad de enfermedades,y que periódicamente se incluye una vacuna más para prevenir otros padecimientos.

El segundo hecho se refiere a que México ha pasado de una media de seis hijos por mujer en la década de los setenta a una media de dos en la actualidad, lo cual indica un fenomenal descenso de la tasa de natalidad que en gran medida debemos adjudicar a la penetración de los programas de planificación familiar. Recordemos, aunque es casi obvio, que dicho descenso tiene que ver directamente con usar técnicas para prevenir el embarazo.

Estos hechos son conocidos por los salubristas mexicanos, y deberían ser asumidos técnica e ideológicamente para desarrollar una concepción más comprensible y optimista respecto de la recepción y aplicación de los grupos sociales de las concepciones y prácticas preventivas.

Pero además deberían articular estos procesos, con los que indican que los grupos sociales desarrollan casi necesariamente saberes preventivos en forma autónoma. Más aún, el cambio de perspectiva le permitiría a los salubristas observar, como veremos luego, que una parte de los saberes preventivos utilizados por los grupos sociales como propios han sido generados a partir de la biomedicina y normalizados por los sujetos como comportamientos cotidianos propios.

Considero que una de las principales tareas de la epidemiología sociocultural debería ser la descripción y análisis de las características, significa- 
do y eficacia de los saberes preventivos utilizados por los diferentes grupos sociales para trabajar a partir de los mismos, articulándolos o no con los criterios preventivos biomédicos. Que una persona no deba transitar por ciertos lugares y a ciertas horas o durante ciertos días; que no deba exponerse a los niños pequeños a miradas y palabras de ciertos sujetos; que no deban comerse ciertos alimentos sobre todo en ciertas situaciones vitales o que las niñas no deban sentarse sobre ciertos lugares fríos constituyen comportamientos preventivos para no contraer determinados padecimientos, como mal de ojo, empacho, susto o mal de orines, los cuales, como sabemos, aparecen estrechamente vinculados con padecimientos alopáticos (Mendoza 1994; Menéndez 1981, 1984, 1990a; Osorio 1994).

Toda una serie de mitos, narraciones y refranes, más allá de sus funciones específicas, presentan criterios preventivos referidos al medio ambiente, animales, personas, seres imaginarios y por supuesto a padecimientos que operan en la vida cotidiana.

Dado el incremento de la inseguridad social actual a nivel objetivo y subjetivo en los diferentes países americanos, las personas y grupos desarrollan estrategias de prevención para evitar ser sujetos de violencia de diferente tipo. Sin embargo, el desarrollo de conductas preventivas respecto de la inseguridad no es nuevo, sino que es parte de las conductas aprendidas, especialmente en términos de género.

Diversas investigadoras describen, en relación con los Estados Unidos, la variedad de estrategias que las mujeres desarrollan cotidianamente para prevenirse de los acosos y violencias de diverso tipo. Y si bien los varones también ponen en práctica estrategias preventivas contra la inseguridad, éstas son mucho más frecuentes y variadas en las mujeres. Las niñas reciben información sobre la manera de sentarse, de vestir, de hablar con los varones; y los niños y las niñas aprenden desde pequeños a no concurrir a casa de amigos cuyas familias sus padres no conocen, así como a no ir al baño en otra casa que la suya. Las mujeres aprenden que cuando van solas deben caminar sobre las banquetas (veredas) del lado de la calle y no del lado de la pared, así como evitar caminar por veredas arboladas, y de no ser posible, caminar por la calle. Estas y otras normas preventivas tienen que ver sobre todo con agresiones sexuales.

Como concluye una estudiosa del problema: “La mayoría de las mujeres tiene que dedicar gran cantidad de energía, tiempo y recursos económicos a protegerse de la delincuencia y a minimizar sus temores: tomar taxis, comprar mace o gas picante, adquirir armas, utilizar estacionamientos cerrados”. Agrega: "Los rituales cotidianos utilizados por hombres y mujeres para protegerse contra el miedo a la delincuencia reproducen y mantienen los estereotipos y las expectativas de género, raza y clase” (Madriz 2001, 143, 186). 
Debemos asumir que las formas de prevención constituyen respuestas sociales que los sujetos y grupos desarrollan casi necesariamente, y que lo paradójico es que esta cualidad social haya sido negada por los encargados de impulsar profesionalmente la prevención.

En América Latina toda una serie de grupos rurales y urbanos utilizaron y utilizan ciertas aguas, especialmente aguas de arroz, de choclo (maíz) o de guayaba, que se pueden beber cotidianamente, pero que además se administran especialmente al sujeto que tiene diarrea. En algunos casos dichas aguas se preparan con azúcar y también con azúcar y sal, y en ciertos grupos se hierven. Y esto mucho antes que la biomedicina promoviera el uso de los sobres de rehidratación oral.

En mi primer trabajo de campo en Yucatán, durante 1977, detecté en una comunidad yucateca de unos 10 mil habitantes que los sujetos en general y en particular si tenían diarreas, y especialmente si eran niños, bebían CocaCola, Sidral o Delaware porque constituían las aguas más potables en las comunidades observadas, comunidades — y lo subrayo - que en su mayoría carecían de agua potable (Menéndez 1981). Más aún, dichas bebidas eran recomendadas por el personal de los centros de salud, por las mismas razones.

Esta práctica la observé ulteriormente en comunidades de otras partes de Yucatán y de México, pero lo que no pude establecer es si esta actitud preventiva/curativa había sido gestada por los grupos en forma autónoma o había sido propuesta por el personal de salud. Pero esto pasa a ser secundario desde nuestro objetivo central, que es proponer una prevención donde se articulen los saberes populares y los biomédicos.

Por supuesto que al señalar estos procesos, no ignoro la importancia decisiva que tuvo la aplicación de las soluciones de rehidratación oral, que contribuyó a reducir radicalmente la mortalidad por enfermedades diarreicas, dado que entre 60 y 70 por ciento de la mortalidad infantil por estos padecimientos se debía a la deshidratación. Si bien en México el Programa Nacional de Hidratación Oral se aplica desde 1984, la rehidratación casera se aplicaba desde la década de los cincuenta, según lo reconocen destacados especialistas mexicanos (Mota Hernández 1990).

Pero es importante destacar que los propios estudios biomédicos indican la resistencia que el personal de salud, incluidos los médicos, tuvieron en América Latina para aplicar e impulsar sistemáticamente la rehidratación oral. Según el coordinador del consejo directivo del control de enfermedades diarreicas de la Secretaría de Salud de México:

El conocimiento teórico de estos nuevos conceptos (sobre hidratación oral) no parece haber sido suficiente en nuestros países latinoameri- 
canos para convencer a la mayoría de los médicos y del personal de salud que tienen a su cargo la responsabilidad de atender a niños con diarrea. Sobre todo cuando la literatura internacional continúa recomendando en forma subliminal las bondades de los "nuevos" antibióticos para la diarrea del turista o las "nuevas fórmulas" libres de lactosa para los niños con diarrea por intolerancia a la leche (Mota Hernández 1990, 256).

Es decir, las resistencias a la prevención - o por lo menos a ciertos tipos de prevención - debemos buscarlas no sólo en los conjuntos sociales legos, sino también en el personal de salud.

La existencia de estos procesos preventivos posibilita la difusión de criterios y actividades de prevención biomédicos, así como, por supuesto, el rechazo de los mismos. Muchas veces ciertas concepciones y prácticas biomédicas preventivas son rechazadas no porque la gente se oponga a la prevención en sí, sino porque contradicen costumbres, incluidas costumbres preventivas, utilizadas por los grupos.

Por supuesto que estos señalamientos no niegan que una parte de los criterios y acciones preventivos utilizados por los grupos pueden tener consecuencias negativas. Pero ello no reduce la importancia de lo que estamos señalando, que es en primer lugar reconocer que todo grupo - $-\mathrm{y}$ subrayo todo grupo- genera y usa saberes preventivos respecto de los procesos que vive real o imaginariamente como amenazantes, y que por lo tanto ello significa que ya existe una disposición positiva hacia la prevención. Y segundo, tratar de identificar cuáles son los mecanismos que operan en estos saberes preventivos para utilizarlos en la formulación y aplicación de las propuestas salubristas.

Los conjuntos sociales manejan potencialmente saberes preventivos que, por lo menos en parte, no son vividos como prevención específica por los sujetos y grupos, dado que constituyen parte de su vida cotidiana, lo cual es lo que debería operar con todo mecanismo preventivo, es decir, desmedicalizarlo y constituirlo en parte normalizada de la vida de los sujetos y grupos. Esto viene a ser otro de los objetivos centrales de la epidemiología sociocultural.

\section{Esquizofrenias metodológicas}

Pese a las posibilidades de articulación que estamos señalando, la revisión de la producción de ambas disciplinas nos indica una fuerte tendencia a la pola- 
rización y a la diferenciación entre las mismas, que se expresan a través de toda una serie de dicotomías.

Considero que las principales diferencias son las que se organizan en torno a los siguientes aspectos: cultural/biológico, local/global, diferencia/homogeneidad, emic/etic, illness/disease, cualitativo/estadístico, "normal”/patológico, generalización/profundización. Existen, por supuesto, otras dicotomías importantes, pero considero que éstas son algunas de las más relevantes y más utilizadas, poniendo de relieve que las dicotomías operan no sólo entre la antropología médica y la epidemiología, sino también en el ámbito de cada una de estas disciplinas, como es el caso de las dicotomías simbólico/económico-político, sujeto/estructura, prácticas sociales/representaciones sociales, microsocial/macrosocial.

Por otra parte, estas dicotomías no son recientes, sino, por el contrario, se han mantenido y en algunos casos profundizado desde la década de los treinta hasta la actualidad. Y así, por ejemplo, toda una serie de autores han cuestionado recientemente la tendencia de los antropólogos médicos no sólo a trabajar exclusivamente con procesos culturales, no sólo a no incluir los procesos de desigualdad socioeconómica en sus descripciones etnográficas, sino a que dicho énfasis en lo cultural tiende a ocultar el papel que desempeñan los procesos económico-políticos y en particular la pobreza en la causalidad y desarrollo de enfermedades como la tuberculosis broncopulmonar o el VIH-sida, así como en el uso de servicios de salud (Castro y Farmer 2003; Farmer 1996, 1997, 2003).

Pero estas y otras críticas al culturalismo antropológico no son nuevas; más aún, caracterizaron a toda una corriente antropológica desarrollada en América Latina entre fines de la década de 1950 y la de 1970, y que justamente cuestionó el papel del culturalismo no sólo en el ocultamiento o negación de ciertos graves problemas de salud de las poblaciones subalternas, sino que criticó el tipo de interpretaciones formuladas que distorsionaban la realidad estudiada, y no tenía capacidad para explicar por lo menos una parte de los procesos estudiados, ni eficacia para reducir los problemas de una población indígena caracterizada en México por tener los peores indicadores de salud comparado con cualquier otro grupo social (Bonfil Batalla 1962; Instituto Nacional Indigenista [INI]/Programa de las Naciones Unidas para el Desarrollo [PNUD] 2000; Menéndez 1981,1990a).

Dicha crítica al culturalismo no negaba la significación de los procesos simbólicos, sino que cuestionaba la reducción de la realidad a aspectos simbólicos, así como la negación o secundarización de procesos económicopolíticos que eran básicos para comprender los procesos de s/e/a.

En términos comparativos debemos señalar que a partir de fines de la década de los sesenta se desarrolló en el ámbito internacional una corriente 
de notables estudios en medicina social, generando importantes aportes no sólo críticos sino propositivos en varios países latinoamericanos (Breilh1979; Donnangelo 1975; Laurell y Noriega 1989 ). Las principales tendencias de esta corriente se caracterizaron por focalizar los aspectos económico-políticos, pero también por excluir o secundarizar los aspectos culturales.

Domina, por lo tanto, una tendencia a la polarización que se reitera constantemente y que, como lo hemos señalado (Menéndez 1998b, 2002), reduce o impide las articulaciones y complementaciones. Más aún, esto ocurre respecto de importantes procesos que han sido recuperados desde la década de los setenta y especialmente de la de los ochenta como objeto de trabajo, como, por ejemplo, el papel del sufrimiento en relación con la enfermedad y con las condiciones de vida.

Toda una serie de autores, entre los que destaca Farmer, han propuesto que la pobreza constituye posiblemente la principal fuente de sufrimiento para gran parte de la población mundial que vive en esa situación, aunque él se refiere específicamente a la población haitiana, donde desarrolló sus estudios e intervenciones médicas y antropológicas. Cada vez en forma más explícita, Farmer $(1996,2003)$ vincula esta situación al sistema capitalista generador de pobreza, y por eso no sólo habla de pobreza y violencia estructural, sino que considera el sufrimiento como parte de esta pobreza y esta violencia generada por dicho sistema, cuestionando a los antropólogos que reducen el sufrimiento a "diferencia cultural".

A su vez, uno de los autores que, a juicio personal, más han impulsado el desarrollo de una epidemiología sociocultural, me refiero a A. Gaines (1992), concluye que los enfoques que buscan explicar el sufrimiento sólo por el sistema capitalista omiten incluir aspectos centrales de tipo cultural y étnico que tienen que ver con dichos sufrimientos. Y que no sólo el sistema capitalista se caracteriza por generar sufrimientos.

Una lectura de la producción etnográfica de ambos autores posibilita observar que lo dominante son los aspectos que favorecerían la articulación y no la diferenciación, pero lo central de sus afirmaciones marca el distanciamiento. Y es esta tendencia al distanciamiento lo que me interesa subrayar, dado que la misma se reitera constantemente a través de nuevas propuestas, que por otra parte a menudo son viejas propuestas retomadas por autores que frecuentemente desconocen su existencia previa.

En los últimos años se ha generado una suerte de disputa entre los que hacen hincapié en que trabajan con experiencias y los que trabajan con representaciones sociales, planteando con frecuencia la incompatibilidad de ambos conceptos en función de los marcos teóricos que los generaron, ya que en un caso el eje se coloca en el sujeto y en el otro en el grupo/cultura; proponiendo que la representación social excluye la subjetividad, y 
dando a entender en forma explícita o tácita que el sujeto no tiene representaciones sociales, o por lo menos que las mismas son secundarias, dado que todo sujeto las resignifica y modifica a partir de sus intencionalidades.

Considero que en muchas de estas propuestas no sólo domina un "teoricismo” (Menéndez 2002) que limita las posibilidades de articulación, dada la radicalidad ideológica con que plantean las diferenciaciones, sino que utilizan concepciones que hace tiempo fueron discutidas pero que ahora se manejan sin retomar justamente los debates teóricos suscitados entre las décadas de los veinte y de los sesenta en torno a los marxismos no mecanicistas, a las diversas propuestas fenomenológicas y a las diferentes variedades neodurkheimianas. En gran medida constituyen redescubrimiento, pero que no asumen la historicidad de sus "nuevas" propuestas.

En principio no cuestionamos que autores y corrientes teóricas prefieran, por diversas razones, trabajar más con aspectos simbólicos que con aspectos biológicos o económico-políticos, ni tampoco que unos opten por trabajar más con experiencias que con representaciones colectivas o con saberes sociales. Lo que cuestionamos es proponer y usar estas dimensiones y conceptos como antagónicos a priori. Consideramos que la selección de las orientaciones teóricas, de los conceptos y metodologías deben darse en función de la problemática a estudiar, de los objetivos buscados, del tipo de actores sociales con que se trabaja.

De allí que el primer paso en la aplicación de una epidemiología sociocultural debiera ser la problematización del proceso de s/e/a a estudiar y/o intervenir y la problematización de los presupuestos teóricos, empíricos y técnicos del propio investigador para, a partir de dichas problematizaciones, comenzar a decidir cuáles son las variables y/o procesos, los conceptos y los actores sociales con los cuales debiera trabajar. Este constituye un trabajo no sólo metodológico, sino además epistemológico que debería darse mediante el desarrollo de investigaciones diseñadas en forma conjunta para, a través de la práctica de la investigación, posibilitar la articulación y complementación a partir de las características particulares de cada disciplina.

Si bien he enumerado algunos de los aspectos que dificultan la posibilidad de generar y sobre todo desarrollar una epidemiología sociocultural, no ignoro sino, por el contrario, asumo positivamente la existencia de toda una producción tanto en antropología médica como en epidemiología que tiende a impulsar el desarrollo de la epidemiología que estamos proponiendo. Los aportes de Cassel, Goldberger o McKeown, por una parte, o las contribuciones de Durkheim, Devereux o A.Young, por otra, posibilitan justamente fundamentar una articulación en términos teóricos y técnicos.

Más aún, desde la propia epidemiología y desde hace más de veinte años, se viene señalando esta necesidad de articulación, como podemos observar- 
lo en las propuestas de Mosley. Éste reconoció que los estudios epidemiológicos sobre mortalidad infantil incluyen un enorme número de variables que se incrementan cada vez más, complicando los modelos analíticos y reduciendo la eficacia de los parámetros estimados. Para evitar esto, hay dos pasos que por lo general se tendrán que dar al planificar la investigación y diseñar los estudios: realizar estudios antropológicos profundos y en pequeña escala como lo propone Ware (1984) (citado por Mosley) para identificar las variables críticas de interés y su interpretación, y especificar con cuidado las relaciones hipotéticas entre las variables, como lo discuten detalladamente Palloni (1981), Shultz (1984) (citados por Mosley) y Mosley (1988, 322).

Subrayamos que Mosley propone una determinada articulación entre las aproximaciones antropológica y epidemiológica que no rechazamos, aunque señalamos que según sea el problema y las condiciones de la investigación, la articulación entre ambas disciplinas puede ser diferente a lo propuesto por este autor. Pero lo importante para nosotros es que Mosley expresa la necesidad y posibilidad de articulación y complementación desde el campo epidemiológico, a partir de analizar sus limitaciones, y creo que es básicamente a partir de reconocer nuestras respectivas limitaciones que podemos ir construyendo una epidemiología sociocultural.

\section{Bibliografía}

Almeida Filho, N. de. 2000. La ciencia tímida. Ensayos de deconstrucción de la epidemiología. Buenos Aires: Lugar.

Antonovski, A. 1979. Health, Stress and Coping. New Perspectives on Mental and Physical Well-Being. San Francisco: Jossey-Bass.

1967. Social Class, Life Expectancy and Overall Mortality. The Milbank Memorial Fund Quarterly (45): 31-73.

Bibeau, G. y E. Corin (editores). 1995. Beyond Textuality. Ascetism and Violence in Anthropological Interpretation. Nueva York: Mouton de Gruyer.

1994. Culturaliser l'épidémiologie psychiatrique. Les systèmes de signes, de sens et d'action en santé mentale. En Marc-Adelard Tremblay ou la construction de l'anthropologie québecoise, dirigido por P. Charest, F. Trudel e Y. Breton, 105-148. Quebec: Presses de l’Université de Laval. 
Bonfil Batalla, G. 1962. Diagnóstico del hambre en Sudzal,Yucatán (un ensayo de antropología aplicada). México: Instituto Nacional de Antropología e Historia/INAH. [Nueva edición: CIESAS, 2006].

Breilh, J. 1979. Epidemiología: economía, medicina y política. Quito: Universidad Central de Ecuador.

Campos, G. W. de S. 2001. Gestión en salud. En defensa de la vida. Buenos Aires: Lugar.

Cassel, J. C. 1976. The Contribution of the Social Environment to Host Resistance. American Journal of Epidemiology 104 (2): 107-123.

1964. Social Science Theory as a Source of Hypotheses in Epidemiological Research. American Journal of Public Health 54 (9): 14821488.

y H. A. Tyroler. 1988. Estudios epidemiológicos de cambios culturales. En El desafío de la epidemiología. Problemas y lecturas seleccionadas, editado por C. Buck, Á. Llopis, E. Nájera y M. Terris, 382-392. Washington: Organización Panamericana de la Salud.

Castellanos, A. 2000. Racismo, multietnicidad y democracia en América Latina. Nueva Antropología XVII (58): 9-26.

Castro, A. y P. Farmer. 2003. El sida y la violencia estructural: la culpabilización de la víctima. Cuadernos de Antropología Social (17): 29-47.

Celis, A. y J. Navas. 1970. La patología de la pobreza. Revista del Hospital General 33 (6): 371-382.

Coreil, J., J. Levin y E. G. Jaco. 1985. Life Style. An Emergent Concept in the Sociomedical Sciences. Culture, Medicine and Psychiatry 9 (4): 243-337.

De Leo, D., J. Bertolote y D. Lester. 2003. La violencia autoinfligida. En Informe mundial de la violencia e de la salud, editado por E. G. Krug, L. L. Dahlberg, J. A. Mercy, A. B. Zwi y P. R. Lozano, 200-231. Washington: Organización Panamericana de la Salud.

De Martino, E. 1975. Mondo popolare e magia in Lucania. Roma/Matera: Basilicata Editrice. 
1961. La terra del rimorso. Contributo a una storia religiosa del sud. Milán: Il Saggiatore. [Hay edición española].

Devereux, G. 1937. Institutionalized Homosexuality on the Mohave Indians. Human Biology 9: 498-527.

Donnangelo, M. C. 1975. Medicina e sociedade: 0 médico e seu mercado de trabalho. São Paulo: Livraria Pioneira.

Dubreuil, G. (editor). 1988. Número especial de Santé, Culture, Health, dedicado a la obra de H. B. M. Murphy v (2): 129-246.

Durkheim, É. 1974 [1897]. El suicidio. México: Universidad Nacional Autónoma de México.

Edward, G. y A. Ariff (editores). 1981. Los problemas de la droga en el contexto sociocultural. Ginebra: Organización Mundial de la Salud. (Cuadernos de Salud Pública 73).

Faerstein, E. 2005. Fórum: raça, racismo e saúde no Brasil. Cadernos de Saúde Pública 21 (5): 1584-1608.

Farmer, P. 2007. Whither Equity in Health? The State of the Poor in Latin America. Cadernos de Saúde Pública 23 (supl. 1): 7-12.

2003. Pathologies of Power: Health, Human Rights and the NewWar on the Poor. Berkeley: University of California Press.

1999. Pathologies of Power: Rethinking Health and Human Rights. American Journal of Public Health 89 (10): 1486-1496.

1997. Social Scientists and the New Tuberculosis. Social Science \& Medicine 44 (3): 347-358.

1996. On Suffering and Structural Violence: A View from Below. Daedalus 125 (1): 260-283.

1992. AIDS and Accusation. Haiti and the Geography of Blame. Berkeley: University of California Press. 
Fry P. H., S. Monteiro, M. Chor-Maio, F. I. Bastos y R. V. Santos. 2007. AIDS tem cor ou raça? Interpretação de dados e formulação de políticas de saúde no Brasil. Cadernos de Saúde Pública 23 (3): 497-523.

Gaines, A. 1992. Ethnopsychiatry: The Cultural Construction of Psychiatries. En Ethnopsychiatry. The Cultural Construction of Professional and Folk Psychiatries, editado por A. Gaines, 3-49. Albany: State University Press of New York.

Gouldner, A. 1977. La dialéctica de la ideología y la tecnología. Los orígenes, la gramática y el futuro de la ideología. Madrid: Alianza.

Grodos, D. y X. Bethume. 1988. Les interventions sanitaires sélectives: Une piège pour les politiques de santé du Tiers Monde. Social Science \& Medicine 26 (9): 879-890.

Hammersley, R. 1994. A Digest of Memory Phenomena for Addiction Research. Review. Adiction 89: 283-293.

Harding, S. (editor). 1993. The 'Racial' Economy of Science. Toward a Democratic Future. Bloomington e Indianapolis: Indiana University Press.

Herman, E. y M. Bentley. 1992. Manuals for Ethnographic Data Collection: Experience and Issues. Social Science \& Medicine 35 (11): 1369-1378.

Inhorn, M. 1995. Medical Anthropology and Epidemiology: Divergences or Convergences? Social Science \& Medicine 40 (3): 285-290.

Instituto Nacional Indigenista (INI)/Programa de las Naciones Unidas para el Desarrollo (PNUD). 2000. Estado del desarrollo económico y social de los pueblos indígenas de México. Dos volúmenes. México: INI.

Jell-Bahlsen, S. 1985. Ethnology and Fascism in Germany. Dialectical Anthropology 9: 313-335.

Krug, E. G., L. L. Dahlberg, J. A. Mercy, A. B. Zwi y P. R. Lozano (editores). 2003. Informe mundial sobre violencia y salud. Washington: Organización Panamericana de la Salud.

La Forgia, G. 1985. Fifteen Years of Community Organization for Health in Panamá: An Assessment of Current Progress and Problems. Social Science \& Medicine 21 (1): 55-65. 
La Jornada. 2007. Muta el virus del Nilo al llegar a América y se vuelve mortal. 14 de agosto.

Laurell, A. C. y M. Noriega. 1989. La salud en la fábrica. Estudio de la siderurgia mexicana. México: Era.

Lenoir, R. 1993. Objeto sociológico y problema social. En Iniciación a la práctica sociológica, editado por P. Champagne et al., 57-102. México: Siglo XXI.

Llobera, J. 1990. La identidad de la antropología. Barcelona: Anagrama.

Madriz, E. 2001. A las niñas buenas no les pasa nada malo. México: Siglo XXI.

Marx, K. 1984. Formas que preceden a la producción capitalista. México: Cuadernos de Pasado y Presente.

Massé, R. 1995. Culture et santé publique. Montreal: Gaetan Morin Éditeur.

Mead, M. 1957 [1949]. Investigación sobre los niños primitivos. En Manual de psicología infantil, dirigido por L. Carmichael, 826-875. Buenos Aires: El Ateneo.

Mendoza, Z. 2004. De la casa del nene al árbol de las placentas. Proceso reproductivo, saberes y transformación cultural entre los triquis de Copala en la Merced. Tesis de doctorado. Guadalajara: CIESAS.

1994. De lo biomédico a lo popular. El proceso salud/enfermedad/atención en San Juan Copala, Oaxaca. Tesis de maestría. México: ENAH.

Menéndez, E. L. 2006. Desaparición, resignificación o nuevos desarrollos de los lazos y rituales sociales. Relaciones (107): 147-178.

2005. Poblaciones abiertas, seguras y privadas: cambios, reorientaciones y permanencias en el sector salud mexicano. En El Estado mexicano: herencias y cambios. Vol. II, coordinado por A. Asís y J. Alonso, 151-191. Guadalajara: CIESAS, Porrúa.

2005. Antropología social como práctica y como representación. Alteridades (29): 65-80. 
2002. La parte negada de la cultura. Relativismo, diferencias y racismo. Barcelona: Edicions Bellaterra.

2001. Biologización y racismo en la vida cotidiana. Alteridades (21): $5-39$.

2001. De la reflexión metodológica a las prácticas de investigación. Relaciones XXII (88): 119-163.

1998. Participación social en salud como realidad técnica y como imaginario social. Cuadernos Médico Sociales (73): 5-22.

1998. Estilos de vida, riesgos y construcción social. Conceptos similares y significados diferentes. Estudios Sociológicos (46): 37-67.

1998. Continuidad/discontinuidad en el uso de conceptos en antropología social. En Antropología social y política. Hegemonía y poder, editado por Grimberg Neufeld y Wallace Tiscornia, 15-36. Buenos Aires: EUDEBA.

1997. El punto de vista del actor: homogeneidad, diferencia e historicidad. Relaciones XVIII (69): 239-270.y R. Di Pardo. 1996. De algunos alcoholismos y algunos saberes. Atención primaria y proceso de alcoholización. México: CIESAS.

1993. Autoatención y participación social: estrategias o instrumentos en las políticas de atención primaria. En Medicina tradicional 500 años después. Historia y consecuencias actuales, editado por C. Roersch, 61-104. Santo Domingo: Instituto de Medicina Dominicana.

1992 (editor). Prácticas, ideologías científicas y populares respecto del alcoholismo en México. México: CIESAS (Colección Miguel Othón de Mendizábal).

1990. Antropología médica. Orientaciones, desigualdades y transacciones. México: Cuadernos de la Casa Chata (Cuaderno 179).

1990. Morir de alcohol. Saber y hegemonía médica. México: Alianza Editorial Mexicana.

1984. Descripción y análisis de las representaciones y prácticas de grupos domésticos sobre la mortalidad en niños menores de cinco años en una comunidad de Guanajuato. M.S. 
1981. Poder, estratificación y salud. Análisis de las condiciones sociales y económicas de la enfermedad en Yucatán. México: Ediciones de la Casa Chata.

1972. Racismo, colonialismo y violencia científica. Buenos Aires: Centro Editor de América Latina.

-y R. B. Di Pardo. 2007. Miedos, riesgos e inseguridades. El papel de los medios, de los profesionales y de los intelectuales en la construcción de la salud como catástrofe. México: CIESAS (en prensa).

2006. Alcoholismo: políticas e incongruencias del sector salud en México. Desacatos (20): 29-52.

2003. Alcoholismo, especializaciones y desencantos: segundo y tercer nivel de atención médica. Informe final de investigación, Ms.

1996. De algunos alcoholismos y algunos saberes. Atención primaria y proceso de alcoholización. México: CIESAS.

y H. Spinelli (coordinadores). 2006. Participación social. ¿Para qué? Buenos Aires: Lugar.

Midanik, L. 1982. The Validity of Self-Reported Alcohol Consumption and Alcohol: A Literature Review. British Journal of Addiction (77): 357-382.

Miranda, J. J. y A. E. Yamin. 2004. Reproductive Health without Rights in Peru. The Lancet 363: 68-69.

Monteiro, S. y L. Sansone (organizadores). 2004. Etnicidade na América Latina: um debate sobre raça, saúde e direitos reprodutivos. Rio de Janeiro: Editoria Fiocruz

Mora y Araujo, M. 2005. El poder de la conversación. Elementos para una teoría de la opinión pública. Buenos Aires: La Crujía Ediciones.

Mosley, W. H. 1988. Determinantes biológicos y socioeconómicos de la sobrevivencia en la infancia. Salud Pública de México 30 (3): 312-328.

Mota Hernández, F. 1990. Estrategias para la disminución de la morbi/mortalidad por diarreas agudas en América Latina. Salud Pública 32 (3): 254260. 
Murphy, H. B. 1982. Comparative Psychiatry: the International and Intercultural Distribution of Mental Illness. Nueva York: Springer/Verlag.

Nueva Antropología. 1985. Vol. viI, no. 28. [Número dedicado a la antropología médica].

Olaiz, G., A. Franco, O. Palma, C. Echarri, R. Valdez, C. Herrera. 2003. Diseño metodológico de la Encuesta Nacional sobre Violencia contra la Mujer. Salud Pública de México 48 (supl. 2): S328-S335.

Oliver, I. 2007. Batallas sin fin. Este país (196): 13.

Organización Mundial de la Salud (OMS)/Organización Panamericana de la Salud (OPS). 2000. Guía internacional para vigilar el consumo de alcohol y sus consecuencias sanitarias. Washington: Organización Mundial de la Salud, Organización Panamericana de la Salud.

Organización Panamericana de la Salud (OPS). 2002. La salud en las Américas. Dos volúmenes. Washington: Organización Panamericana de la Salud.

Ortega, J. 1999. Proceso reproductivo femenino: saberes, género y generaciones en una comunidad maya de Yucatán. Tesis de doctorado. Zamora: El Colegio de Michoacán.

Osorio, R. M. 1994. La cultura médica materna y la salud infantil. Tesis de maestría. México: Escuela Nacional de Antropología e Historia.

Paganini, J. y M. Rice. 1989. Participación social en los sistemas locales de salud. Washington: Organización Panamericana de la Salud.

Peirano, M. G. 1997. Onde está a antropología? Mana 3 (2): 67-102.

Proctor, R. 1988. Racial Hygiene. Medicine under the Nazis. Cambridge, Massachussets: Harvard University Press.

Rifkin, S. y G. Walt. 1998. Selective or Comprehensive Primary Health Care. Social Science \& Medicine 26 (9). [Número dedicado a la atención primaria.]

Room, R. y G. Collins (editores). 1983. Alcohol and Disinhibition: Nature and Meaning of the Link. Rockville: National Institute on Alcohol Abuse and Alcoholism. 
Secretaría de Salud. 2004. Estadísticas de mortalidad en México: muertes registradas en el año 2002. Salud Pública de México 46 (2): 169-184.

2001a. Programa Nacional de Salud 2001-2006. México: Secretaría de Salud.

. 2001 b. Salud México 2001. Información para la rendición de cuentas. México: Secretaría de Salud.

Seppa, K. 2006. El secreto del consumo peligroso de bebidas. Adicciones 18 (2): 105-110.

Stern, M. 2006. Esterilización en nombre de la salud pública: raza, inmigración y control reproductivo en California en el siglo xx. Salud Colectiva 2 (2): 150-189.

Terris, M. 1980. Estudios de Goldberger sobre la pelagra. México: Instituto Mexicano del Seguro Social.

Tousignant, M. 1989. La pauvreté: cause ou espace des problèmes de santé mentale. Santé mentale au Québec, XIV (2): 91-104.

Weber, M. 1987. Economía y sociedad. Esbozo de sociología comprensiva. México: Fondo de Cultura Económica.

Yarzábal, L. 1985. La tortura como enfermedad endémica en América Latina: sus características en Uruguay. Nueva Antropología 28:75-92.

Williams, F. (editor). 1977. Why the Poor Pay More. Londres: MacMillan Press. 